\title{
LAS JUSTIFICACIONES DE LA REGLA DE QUÓRUM SUPRA-MAYORITARIA DE LAS LEYES ORGÁNICAS CONSTITUCIONALES
}

["The Justifications of the Above Majority Rules of a Quorum of the Constitutional Organic Acts"]

\author{
Sergio Verdugo* \\ Universidad del Desarrollo, Santiago de Chile
}

\begin{abstract}
RESUMEN
Se defiende la regla de quórum supramayoritario de las leyes orgánicas constitucionales en determinados casos. Se dividen sus justificaciones en dos grupos (general y especial), y se verifica que los críticos no han abandonado el primer nivel del debate, lo que es inconsistente con un modelo argumentativo que considere el resto de
\end{abstract}

\begin{abstract}
In this work the above majority rules of a quorum of the constitutional organic acts is advocated in certain cases. The justifications are divided into two groups (general and special), and it is confirmed that the critics have not abandoned the first level of debate, which is not consistent with an argumentative model considering the
\end{abstract}

ReCibido el 29 de octubre y ACEPTADo el 7 de diciembre 2012.

* Magíster en Derecho por la Universidad de California, Berkeley; magíster en Derecho público por la Pontificia Universidad Católica de Chile. Profesor de Derecho constitucional e investigador del Centro de Justicia Constitucional de la Facultad de Derecho de la Universidad del Desarrollo. Correo postal: Facultad de Derecho, Universidad del Desarrollo, Av. Plaza 680, San Carlos de Apoquindo, Las Condes, Santiago. Correo electrónico: sverdugor@udd.cl Agradezco las observaciones de los profesores José Manuel Díaz de Valdés, Ignacio Covarrubias, José Francisco García, Níckolas Laport y Nicolás Enteiche. Además, agradezco la colaboración de los ayudantes de la Dirección de Investigación de la Facultad de Derecho de la Universidad del Desarrollo, Carla Ottone y Nicolás Galli. 
los arreglos institucionales relevantes y las razones específicas que fundamentan las leyes orgánicas en particular.

\section{Palabras Clave}

Leyes orgánicas constitucionales Quórum - Super-mayoría. other relevant institutional arrangements and the specific reasons that are basis of the organic acts in particular.

\section{KEYWORDS}

Constitutional organic acts - Quorum - Above-majority

\section{INTRODUCCIÓN}

Se discute acerca de la conveniencia de poseer un sistema legislativo que considere quórums especialmente altos para tramitar proyectos de ley referidos a determinadas materias calificadas por la constitución. El objeto de crítica ha sido el sistema de leyes orgánicas constitucionales (= "ley org. const." o las "leyes org. const.", según corresponda) establecido entre nosotros por el constituyente de 1980. Los argumentos democráticos y constitucionales se han mezclado con razones políticas relacionadas con la legitimidad de origen de este sistema de quórums (proveniente del régimen militar que gobernó Chile entre 1973 y 1990) y han motivado la presentación de diversos proyectos de reforma constitucional que se han discutido en el Congreso ${ }^{1}$. Sin embargo, y como demostraré en este trabajo, el debate nacional adolece de serios defectos que deben corregirse. Para ello, presentaré una propuesta que permita ordenar los argumentos en diferentes niveles y analizar las razones entregadas en su mérito, distinguiendo cuestiones que parecen necesarias y relacionando materias que no pueden dejar de observarse si se quiere tener una mirada amplia y completa de los problemas del sistema constitucional chileno ${ }^{2}$.

${ }^{1}$ Han existido múltiples proyectos de reforma constitucional en la materia. Algunos proyectos han intentado hacer equivalente el quórum de las leyes orgánicas constitucionales al de las leyes de quórum calificado (proyectos de ley Boletines $\mathrm{N}^{\circ}$ 7876-07 y 4.028-07). También ha existido un proyecto que persigue aumentar el quórum de las leyes org. const. (Boletin $\mathrm{N}^{\circ} 2149-07$ ) y ha habido otros, de autores pertenecientes a diversos partidos políticos, que persiguen agregar materias nuevas al quórum de leyes org. const. (Boletines $\mathrm{N}^{\circ}$ 7867-07, 6950-07, 6232-07, 5289-07, 4498-07, 2029-07).

${ }^{2}$ Como ese trabajo se focaliza en la regla súper-mayoritaria y no en el rol del Tribunal Constitucional respecto de las leyes org. const., hago presente que es compatible argumentar que el control obligatorio tiene problemas importantes, con defender la regla súper-mayoritaria asociada solamente a un control eventual de constitucionalidad. Sobre los problemas del control preventivo obligatorio, véase: De la Fuente, Felipe, Problemas de quórum en la tramitación de las leyes interpretativas de la Constitución, orgánicas constitucionales y de quórum calificado, en Revista de Derecho de la Univer- 
Existen dos tipos diferentes de justificaciones para la regla legislativa de quórum súper-mayoritario contenida en una ley org. const. El primer grupo de justificaciones $i$ ) dice relación con una fundamentación general de la regla de quórum, la que es útil para discutir la misma sin ser relevante el tipo específico de materia que quiere rigidizar. Así, por ejemplo, dentro de este tipo de justificaciones se suele argumentar que una regla alta de quórum legislativo tiende a producir mayor estabilidad político-normativa, que ella es útil para proteger a las minorías frente al poder de las mayorías y que de este modo se resguarda el desarrollo complementario del diseño constitucional. A este tipo de razones las denominaré j u s $\mathrm{t}$ i f i c a c i o n e s g e n e r a les. Estas justificaciones generales suelen ser criticadas con contraargumentos que son, también, de carácter general. Entre otras ideas, se suele señalar que la regla super-mayoritaria le entrega un veto a las minorías políticas que reduce el poder de las mayorías, con lo que se restringiría el sistema democrático y se afectaría la igualdad en el valor de los votos parlamentarios.

Por otra parte, existe un segundo grupo de justificaciones $i$ ), las que se asocian con las materias específicas que se persigue rigidizar mediante el establecimiento de un quórum legislativo especialmente alto para su creación, reforma o eliminación. Este tipo de razones no son comunes a todas las reglas súper-mayoritarias, ya que ellas se basan en fundamentos especiales que varían atendiendo las particularidades de la regulación de la institución de que se

sidad Católica de Valparaíso, 14 (Valparaíso, 1992), pp. 313-342.; Shapiro, Martín, Revisión judicial a priori y a posteriori: los modelos norteamericano y europeo, en Revista Chilena de Derecho, 20 (Santiago, 1993), pp. 475-479; Pfeffer, Emilio, Algunos problemas que se derivan del control obligatorio de constitucionalidad que ejerce el Tribunal Constitucional sobre las leyes orgánicas constitucionales, en Ius et Praxis, 1 (Santiago, 1998) 4, pp. 259-268.; BoRDalí, Andrés, Análisis critico del control preventivo y represivo de constitucionalidad de las normas juridicas por los tribunales constitucionales, en Nogueira, Humberto (editor), Jurisdicción constitucional en Chile y América Latina: presente y prospectiva (Santiago, LexisNexis [2005]), pp. 213-254.; BuCHHEISTER, Axel - Sото Sebastián, Criterios para la calificación de normas orgánico constitucionales en la jurisprudencia del Tribunal Constitucional, en Revista Chilena de Derecho, 32 (Santiago, 2005); Aldunate, Eduardo, Problemas del control preventivo de constitucionalidad de las leyes, en Revista de Estudios Constitucionales, 1, (Talca, 2005) 3, pp. 119-126.; Verdugo, Sergio, Control preventivo obligatorio: ange y caida de la toma de razón al legislador, en Revista de Estudios Constitucionales, 1 (Talca, 2010); y SIERRA, Lucas - MAC-CluRE Lucas, Frente a las mayorias: leyes supramayoritarias y Tribunal Constitucional en Chile (Santiago, Centro de Estudios Públicos, 2011), pp. 13-166. Por otra parte, cabe hacer presente que, sin perjuicio de que soy crítico del control preventivo obligatorio, he defendido las leyes org. const. en el plano de los argumentos generales, sin considerar el marco argumentativo que propongo en este trabajo. VERDUGO, Sergio, Regla de mayoría y democracia: el caso de las leyes orgánicas constitucionales, en Revista Actualidad Jurídica, 20 (Santiago, 2009). 
trate, y de su importancia. De esta manera, por ejemplo, no es lo mismo la justificación de la exigencia súper-mayoritaria para la legislación municipal (que protege autonomías locales) que aquella que se utiliza para defender las competencias de los órganos de control del poder, como ocurre con la ley del Tribunal Constitucional o la Contraloría General de la República. Este tipo de razones las llamaré j u s t if i c a c i o n e s e s p e c i a l e s. Como veremos, esta clase de fundamentos son muy comunes en el Derecho Comparado; sin embargo, han estado generalmente ausentes del debate chileno y, como es lógico, ellas no han sido respondidas por los críticos.

En este trabajo, constataré que los autores nacionales sólo han discutido en el plano de las justificaciones generales, en circunstancias que los argumentos derivados de este tipo de justificaciones son dependientes del segundo tipo de razones (las especiales), las que no deberían quedar ausentes de debate. Además, discutiré la orientación con que los críticos de las leyes org. const. han pretendido eliminar la regla de súper-mayoría, mostrando que, en general, ellos no consideran que todos los modelos de quórums legislativos son parte de un sistema político más amplio, donde diferentes arreglos institucionales contra-mayoritarios se relacionan y afectan recíprocamente. Para proponer la reforma de cualquiera de esos instrumentos (en este caso, de las leyes org. const.) es necesario examinar la manera en que dicha reforma impactará en el resto del proceso político.

Mostrando las deficiencias del debate actual, propondré un marco para discutir acerca de la regla súper-mayoritaria contenida en las leyes org. const., promoviendo un debate sustentado en una correcta orientación de las justificaciones, y no en la crítica política que suele asociarse a ellas (en tanto parte del diseño institucional del régimen militar). Si bien las leyes org. const. tienen una explicación histórica en Chile, las razones que permiten sostenerlas son independientes de su origen, y ellas pueden ser utilizadas en diferentes contextos, tanto en otras Constituciones, en pasadas o futuras reformas constitucionales o en el desarrollo continuo del constitucionalismo chileno bajo la tantas veces modificada e interpretada Constitución de $1980^{3}$. Hago

\footnotetext{
${ }^{3}$ Por lo demás, las razones que justifican las leyes org. const. son aplicables a aquellas que fueron creadas en democracia y, probablemente, a otras instituciones contramayoritarias existentes en nuestro sistema político. El constituyente democrático ha utilizado la técnica de las leyes org. const. en reiteradas ocasiones. Este es el caso: $i$ ) de las atribuciones de los consejos regionales y de la regulación de consejo económico y social, provincial y comunal en los primitivos artículos 102, 105 y 107 (Ley $\mathrm{N}^{\circ}$ 19.097, de 1991); ii) de la reforma constitucional que ordena la creación de una ley org. const. para el Ministerio Público en el artículo 84; (Ley No 19.519, de 1997); iii) de la regulación de los territorios de Isla de Pascua y el Archipiélago Juan Fernández en el artículo 126 bis (Ley $\mathrm{N}^{\circ} 20.193$, de 2007); iv) de la regulación del registro electoral en el artículo 18 (Ley $\mathrm{N}^{\circ} 20.337$, de 2009); v) de la constitución de asociaciones
} 
presente, además, que a lo largo de este trabajo procuraré utilizar ejemplos extraídos de sistemas políticos comparados, como una manera de demostrar que la premisa de muchos autores relativa a que las leyes org. const. son únicas en las democracias constitucionales actuales, es un mito ${ }^{4}$.

Seguiré el siguiente orden. En primer lugar, sintetizaré el debate chileno actual, adelantando algunas deficiencias de este y constatando que el mismo se ha mantenido en el plano de las justificaciones generales, pese a que no considera ni valora todas ellas (II). En seguida, explicaré por qué es importante que las justificaciones de tipo general consideren una perspectiva amplia del sistema político. Argumentaré que los propósitos del arreglo institucional de los quórums parlamentarios son dependientes de la coexistencia de otros instrumentos presentes en el proceso legislativo y, aunque la revisión de unos no supone necesariamente la reforma de otros, el examen general del proceso político no puede estar ausente (III). En tercer término, explicaré la importancia de valorar las justificaciones especiales de las reglas súper-mayoritarias, constatando la conexión que ellas tienen con el plano de discusión general y proponiendo un marco para que el debate sobre las leyes org. const. continúe bien orientado. Para ello, utilizaré ejemplos extraídos de la Constitución chilena y, también, de arreglos institucionales de otras

de municipalidades en el artículo 118 (Ley $\mathrm{N}^{\circ} 20.346$, de 2009); vi) de la regulación de la elección directa de los consejeros regionales en el artículo 113 (Ley $\mathrm{N}^{\circ} 20.390$, de 2009); vii) de la enumeración de funcionarios que deberán declarar sus intereses y patrimonio en el artículo 8 inciso $3^{\circ}$ (Ley $\mathrm{N}^{\circ} 20.414$, de 2010); y viii) de la regulación de las elecciones primarias en el artículo 19, $\mathrm{N}^{\circ} 15$ (Ley 20.414, de 2010). Todos estos casos demuestran que la utilización de las leyes org. const. es una técnica comúnmente empleada en democracia.

${ }^{4}$ Las leyes org. const. chilenas fueron propuestas por la Comisión de Estudios para la Nueva Constitución a raíz de una sugerencia que pretendía imitar el modelo francés sobre leyes orgánicas. Junto al español, las leyes org. const. francesas han servido de referente para la literatura chilena. Sin embargo, como el quórum de las leyes org. const. en ambos países no es especialmente alto, se ha dicho (y con razón) que ellas son un mal ejemplo. Con todo, la existencia de quórums legislativos calificados es frecuente en otros sistemas políticos (como en Austria, Portugal, Bélgica, India, EE.UU., etc.), por lo que es falsa la crítica que sostiene que la democracia siempre supone la regla de mayoría simple y que el diseño constitucional chileno es una rara excepción, como lo hace ToHÁ, Carolina, Constitución y Bicentenario: la superación de un déficit histórico, en Fuentes, Claudio (editor). En nombre del pueblo: debate sobre el cambio constitucional en Chile (Santiago, Heinrich Böll Stiftung - ConoSur e ICSO Diego Portales, [2010]), p. 269. Sobre la discusión de estas materias en la Comisión de Estudios para la Nueva Constitución, véase especialmente las siguientes sesiones: $\mathrm{N}^{\circ} 18$, de 22 de noviembre de 1973; $\mathrm{N}^{\circ} 344$, de 4 de abril de 1978; $\mathrm{N}^{\circ} 353$, de 19 de abril de 1978; $\mathrm{N}^{\circ} 358$, de 25 de abril de 1978; $\mathrm{N}^{\circ} 389$, de 27 de junio de 1978. 
democracias en el mundo (IV). Finalmente, sintetizaré las conclusiones de este trabajo $(\mathrm{V})$.

\section{El Debate Chileno y sus problemas}

\section{Los primeros trabajos sobre las leyes orgánicas constitucionales}

Existen pocos trabajos que hayan analizado el problema del quórum súper-mayoritario de manera sistemática ${ }^{5}$. Un primer grupo de artículos pertenecen a una etapa temprana que se desarrolló poco después de la entrada en vigencia de la Constitución de $1980^{6}$. Sin embargo, en esta etapa los autores no profundizaron en las razones que justificaban las leyes org. const. Aunque, en general, estos trabajos parecen justificar la existencia de ellas en motivos de tipo general, su enfoque privilegió el estudio de su naturaleza jurídica, la relación de las leyes org. const. con la potestad reglamentaria y su jerarquía, entre otros ${ }^{7}$. De esta manera, para la materia que es objeto de este artículo, este grupo de trabajos aporta poco, aunque a partir de ellos podemos construir un primer grupo de argumentos que se asocia con el entendimiento que los redactores de la Constitución y el Tribunal Constitucional tuvieron de las leyes org. const.

En esta etapa temprana, se encontraba presente la idea de que las leyes org. const. eran el desarrollo complementario de nuestra breve Constitución, y que su contenido correspondía a cuestiones fundamentales que debían ser adoptadas de una manera lo más cercana posible a la "voluntad general" , de manera de darle legitimidad a aspectos relevantes de nuestro sistema político y jurídico 9 . Junto con ello, se señalaba que este tipo de materias requerían de

${ }^{5}$ Probablemente el trabajo más completo sea el de Sierra, Lucas - Mac-Clure Lucas, cit. (n. 2), quienes se manifiestan críticos.

${ }^{6}$ Dentro de este tipo de trabajos, encontramos por ejemplo a Ríos, Lautaro, Las leyes orgánicas constitucionales, en Revista Chilena de Derecho, 10 (Santiago, 1983); Bulnes, Luz, La ley orgánica constitucional, en Revista Chilena de Derecho, 11 (Santiago, 1984); y CALDERA, Hugo. Ley orgánica constitucional y potestad reglamentaria, en Revista Chilena de Derecho, 11 (Santiago, 1984).

${ }^{7}$ También existen trabajos más recientes que, en general, adoptan este enfoque más asociado a la dogmática jurídica tradicional. Buenos ejemplos son los trabajos de SILVA Bascuñán, Alejandro, Tratado de Derecho constitucional (Santiago, Editorial Jurídica, 2000), VII, pp. 26-39; y Henrí uez, Miriam, Las fuentes formales del Derecho, (Santiago, LegalPublishing, 2009), pp. 63-71.

${ }^{8}$ Este argumento fue utilizado por primera vez por Raúl Bertelsen en la Comisión de Estudios para la Nueva Constitución, sesión $N^{\circ} 344,4$ de abril de 1978. Véase también Bulnes, Luz, cit. (n. 6), p. 239.

${ }^{9}$ Tribunal Constitucional, rol $\mathrm{N}^{\circ} 255,20$ de mayo de 1995 , considerando $5^{\circ}$. 
grados importantes de legitimidad institucional en el tiempo ${ }^{10}$.

En esta época, la literatura era generalmente acrítica, y pasaron algunos años antes de que se comenzara a polemizar respecto de la legitimidad y conveniencia de la institución en estudio. En efecto, y probablemente debido al papel que jugaba el Tribunal Constitucional, a partir de la década de los '90, algunos autores comenzaron a constatar algunos problemas prácticos en el ejercicio del control preventivo obligatorio ${ }^{11}$ y a cuestionar la existencia de este tipo de control ${ }^{12}$. No todas las críticas al control preventivo eran, en realidad, cuestionamientos a las leyes org. const. en su conjunto, sino que a cuestiones específicas de ellas o a la manera en que los diferentes actores se comportaban frente a ellas ${ }^{13}$. Hoy, sin embargo, es común encontrar autores que son críticos de las leyes org. const. en su integridad, incluyendo la regla súper-mayoritaria, el sistema de control preventivo y la función del Tribunal Constitucional ${ }^{14}$.

\section{La critica democrática a las leyes orgánicas constitucionales.}

En paralelo a la discusión sobre el control preventivo de las leyes org. const., un grupo de críticas que invocaban la democracia como fundamento central, comenzaron a desarrollarse en contra de la regla súper-mayoritaria contenida en este tipo de leyes. En general, ellas pueden resumirse en tres argumentos:

En primer lugar $i$ ) se dice que con la creación de las leyes org. const., el régimen militar habría buscado dificultar las reformas a la estructura de su sistema constitucional ${ }^{15}$, protegiendo la "idea guzmaniana de 'democracia

${ }^{10}$ Por ejemplo, Tribunal Constitucional, rol №255, 20 de mayo de 1995, considerando $5^{\circ}$; CRUZ-Coke, Carlos, Manual de educación cívica ( $8^{a}$ edición, Santiago, Ediciones Universidad del Desarrollo, 2005) p. 159; Verdugo, Sergio, Regla de mayoría, cit. (n. 2), pp. 607-609.

${ }^{11}$ De La Fuente, Felipe, Problemas de quórum en la tramitación de las leyes interpretativas de la Constitución, orgánicas constitucionales y de quórum calificado, en Revista de Derecho de la Universidad Católica de Valparaíso, 14 (Valparaíso, 1992), pp. 313-342; Pfeffer, Emilio, cit. (n. 2), pp. 259-268; Bordalí, Andrés, cit. (n. 2), pp. 213-254.; Buchheister, Axel - Soto Sebastián, cit. (n. 2); Aldunate, Eduardo, cit. (n. 2), pp. 119-126.

${ }^{12}$ Shapiro, Martín, cit. (n. 2).

${ }^{13}$ Así, hoy es posible encontrar y distinguir críticas al control preventivo obligatorio que pertenecen a autores que defienden la existencia de la regla legislativa de supermayoría en ciertas ocasiones, como en VERDUGo, Sergio, Control preventivo obligatorio, cit. (n. 2).

${ }^{14}$ Como Correa, Rodrigo, Tribunal Constitucional, en Revista de Derecho de la Universidad Adolfo Ibáñez, 2 (Santiago, 2005); y Sierra, Lucas, cit. (n. 2).

${ }^{15}$ Bassa, Jaime, Democratización y mutación constitucional, en Cazor, Kamel SAlas, Carolina (coordinadores), Estudios Constitucionales (Santiago, Asociación 
protegida"'16, lo que habría sido producto de la desconfianza que dicho régimen habría tenido hacia las mayorías ${ }^{17}$.

En segundo lugar $i i$ ) se indica que las minorías podrían vetar el accionar de las mayorías, lo que es contrario al principio democrático ${ }^{18} \mathrm{y}$ hace muy difícil que un Gobierno mayoritario pueda avanzar en su agenda legislativa, restándole flexibilidad al proceso de formación de la ley y favoreciendo el statu quo $^{19}$. Cabe hacer presente que este argumento es otra forma de ver la idea de que las súper-mayorías persiguen la estabilidad política-institucional del órgano que regulan. En otras palabras, donde algunos ven falta de flexibilidad y defensa de statu quo (algo normalmente peyorativo) otros ven estabilidad (algo normalmente positivo). En efecto, la mayoría calificada incrementa los niveles de estabilidad justamente porque introduce un "jugador con veto" ("veto player") más ${ }^{20}$. Como puede apreciarse, esta consecuencia de las leyes

Chilena de Derecho Constitucional, Librotecnia [2010]), pp. 36-37; Fuentes, Claudio, Elites, opinión pública y cambio constitucional, en Fuentes, Claudio (editor), En nombre del pueblo, cit. (n. 4), pp. 52-53.

${ }^{16}$ Atria, Fernando, Participación y alienación politica: el problema constitucional, en Fuentes, Claudio (editor), En nombre del pueblo, cit. (n. 4), p. 176; Couso, Javier - Coddou, Alberto, Las asignaturas pendientes de la reforma constitucional chilena, en Fuentes, Claudio (editor), en Nombre del pueblo, cit. (n. 4), pp. 192-193 y 198-199; Szmulewicz, Esteban, Democracia, gobierno de la mayoría y leyes orgánicas constitucionales. Parte II. Asuntos Públicos, Informe 979, 2012-II [visible en internet: http:// www.asuntospublicos.cl/wp-content/uploads/2012/07/979.pdf], p. 2.

${ }^{17}$ Sierra, Lucas, cit. (n. 2), p. 23. En su trabajo, este autor documenta algunos pasajes del origen de las leyes org. const. en el régimen militar, mediante los cuales intenta conectar la idea de la desconfianza general del mismo hacia las mayorías con las leyes org. const. .

${ }^{18}$ Correa, Rodrigo, cit. (n. 14), p. 740; MuÑoz, Fernando, Leyes orgánico-constitucionales insatisfactoria rigidización de la democracia, en Anuario de Derecho Constitucional Latinoamericano, 1 (2006), pp. 115-129; Henrí Uez, Miriam, cit. (n. 7), p. 71; ATRIa, Fernando, cit. (n. 16), pp. 175-176; García, Gonzalo, Reformas politicas presentadas por el Ejecutivo, en Couso, Javier (editor), Anuario de Derecho Público (Santiago, Ediciones UDP, 2011), pp. 169-170; SzMULEwiCz, Esteban, 2012, Democracia, gobierno, cit. (n. 4).

${ }^{19}$ Henrí uez, Miriam, cit (n. 7), p. 71; Couso, Javier - Coddou, Alberto, cit. (n. 16), p. 198.

${ }^{20}$ TSEBELIS, George, Jugadores con veto: cómo funcionan las instituciones politicas (México, Editorial Fondo de Cultura Económica, 2006), p. 201. Hago presente que la expresión "jugador con veto" responde a un anglicismo ("veto player") que no corresponde al sentido tradicional que la literatura constitucional chilena le suele atribuir. En efecto, mientras ésta asocia el "veto" con la facultad del Presidente de la República para formular observaciones a los proyectos de ley, en la literatura de Ciencia política (especialmente en la teoría de juegos), la expresión "veto" se relaciona con la capacidad de ciertas instituciones para frenar un proceso político, en este caso, legislativo. Es lo 
org. const. puede servir para argumentar en un sentido u otro, dependiendo de si se valora o no dicha estabilidad ${ }^{21}$.

Finalmente iii), una última crítica a las leyes org. const. indica que, debido al veto de las minorías, la regla súper-mayoritaria afectaría el valor individual de cada voto parlamentario, con lo que se alteraría la igualdad de voto que toda democracia representativa supone ${ }^{22}$.

Los tres argumentos anteriores se verían fortalecidos (o agravados) por dos razones. La primera $i$ ) indica que la existencia del sistema electoral binominal tendría una tendencia a producir empates parlamentarios, por lo que la regla de súper-mayoría se hace especialmente difícil de alcanzar, lo que hace crecer la capacidad de veto de la minoría ${ }^{23}$. En segundo lugar ii) la objeción a las leyes org. const. se agrava debido al accionar del Tribunal Constitucional, el que parece haber expandido el tipo de materias que deberían ser propias de ley org. const., con lo que la súper-mayoría se ha vuelto muy frecuente en la práctica legislativa ${ }^{24}$. La eliminación del control preventivo obligatorio haría disminuir la anomalía democrática de las leyes org. const., lo que también se produciría si el Tribunal Constitucional tuviera una actitud más contenida en el ejercicio de sus atribuciones de control ${ }^{25}$.

que ocurriría cuando, por ejemplo, si el Senado rechaza un proyecto aprobado por la Cámara de Diputados; si una minoría parlamentaria logra obstruir la aprobación de un proyecto de ley (mediante el "filibuster" o a través de una regla de quórum o de asistencia especial); si el Tribunal Constitucional declara inconstitucional un proyecto de ley; o si el Jefe de Estado no patrocina una iniciativa parlamentaria en una materia que es de su iniciativa exclusiva, entre otros. Hago presente que, en adelante, la expresión "veto" o "jugador con veto", será utilizada en este segundo sentido.

${ }^{21}$ Por eso, autores como Tsebelis, George cit. (n. 20), p. 213, definen la estabilidad como "la imposibilidad de un cambio importante del statu quo".

${ }^{22}$ En esta parte, los críticos suelen citar a Böckenforde, quien vincula la idea del gobierno de las mayorías con la igualdad de los ciudadanos. Así, se dice que los "votos sólo pueden ser contados y no ponderados”. Sierra, cit. (n. 2), p. 15; Szmulewicz, E., cit. (n. 18), pp. 4-5. Este argumento también ha sido utilizado brevemente por HENRÍQUEZ, Miriam, cit. (n. 7), p. 71.

${ }^{23}$ Zapata, Patricio, Justicia constitucional (Santiago, Editorial Jurídica de Chile, 2008.), pp. 402-403; Couso, J. - Coddou, A., cit. (n. 16), p. 198; Szmulewicz, E., cit. (n. 18), p. 3.

${ }^{24}$ Sierra, cit. (n. 2), p. 31-59. También, ver Correa, Rodrigo cit. (n. 8), pp. 740745; Muñoz, Fernando, cit. (n. 18), pp. 126-127; Zapata, P., cit. (n. 23), pp. 395458; Couso, J. - Coddou, A., cit. (n. 16), p. 199; Bassa, J., cit. (n. 15), pp. 38-39. Sobre la jurisprudencia del Tribunal Constitucional y la manera en que el Congreso califica los preceptos orgánicos constitucionales, ver además el trabajo de BUCHHEIsTer, A. - Soto, S., cit. (n. 2).

${ }^{25}$ Así lo concede Sierra, cit. (n. 2), p. 17. 


\section{Los problemas de la crítica democrática a las leyes orgánicas constitu-} cionales.

Las críticas recién enunciadas adolecen de cuatro problemas: primero i) ellas confunden el argumento político frente al origen de la norma con las consecuencias de la misma; segundo $i i$ ) ellas no contienen un análisis completo del sistema político actual; tercero $i i i)$ para su funcionamiento, ellas requieren de la construcción de un concepto de democracia, igualdad y representación política; y cuarto $i v$ ), ellas han olvidado referirse al nivel de las justificaciones especiales de las leyes org. const. Veamos por separado cada uno de estos problemas.

En primer lugar $i$ ), debe afirmarse que algunos críticos suelen mezclar los argumentos políticos contra el plan constitucional del régimen militar (1973-1990) con aquellas razones que, descontextualizadas, podrían servir para justificar o criticar las leyes org. const. Si bien el contexto siempre es relevante para el análisis de problemas jurídicos aplicados, en muchas ocasiones la separación del tipo de argumentos es útil para ponderar el peso de las razones que se encuentran presentes en el debate. Ello serviría, por ejemplo, para discutir la inclusión de nuevas leyes org. const. (como ya ha ocurrido en democracia), para eliminar algunas de ellas del sistema constitucional actual o para reformular la manera en que ellas están redactadas, o la forma en que ellas actúan en la práctica del control preventivo o por parte del propio legislador. Por esto, y como adelanté en la introducción, en este trabajo no analizo el problema del origen político de estas normas, ya que me interesa aislar la justificación y los beneficios de ellas.

En segundo lugar ii), las críticas recién citadas generalmente sólo analizan el diseño de las leyes org. const. en general y, salvo por algunas relaciones con el sistema electoral binominal ${ }^{26} \mathrm{y}$ con los poderes del Tribunal Constitucional ${ }^{27}$, ellas no consideran el resto de instrumentos contramayoritarios existentes en el proceso legislativo. Las leyes org. const. forman parte de un sistema de vetos legislativos (bicameralismo, veto presidencial, etc.) que sigue diversos fines. La manera en que ellos actúan no es estática, sino que dinámica, por lo que el análisis de uno de estos elementos no está completo si no se analiza la manera en que el resto de ellos interactúan. Lo importante no es la manera en que los quórums le entregan poder de veto a las minorías, sino que la manera en que este veto contribuye a conducir (o a no conducir) el proceso legislativo en alguna dirección. Profundizaré sobre este problema más adelante.

${ }^{26}$ Por ejemplo, Zapata, P., cit. (n. 23), pp. 402-403 y Szmulewicz (2012-I) p. 3.

${ }^{27}$ Por ejemplo, Correa, R., cit. (n. 8), pp. 740-745; Zapata, P., cit. (n. 23), pp. 395-458 y SiERRA, cit. (n. 2), p. 31-59. 
En tercer lugar iii), las críticas dicen invocar fundamentos democráticos. Ellas asumen que la regla de mayoría simple es el requerimiento de toda democracia, cuestión que admite respuesta: para que dicho argumento funcione, debe demostrarse que toda democracia necesita de mayoría simple en cualquier materia. Sin embargo, no todas las democracias que respetamos consideran mayoría simple para todas las materias legislativas. Entre varios otros sistemas democráticos prestigiosos, podemos observar los casos de Estados Unidos, Dinamarca, Austria, Uruguay y Costa Rica ${ }^{28}$. En efecto, la Constitución de los EE.UU. requiere de $2 / 3$ de senadores para aprobar un tratado internacional ${ }^{29}$; las "leyes constitucionales federales" austríacas requieren de un quórum legislativo de $2 / 3$ con la presencia obligatoria mínima de la mitad de los miembros ${ }^{30}$; la Constitución danesa requiere de un quórum de $5 / 6$ para entregar poder político a autoridades internacionales ${ }^{31}$; la Constitución uruguaya requiere de $2 / 3$ para la regulación del sufragio y las elecciones (artículo 77, $\mathrm{N}^{\circ} 7$ ) y para "conceder monopolios" (artículo 85, $\mathrm{N}^{\circ}$ 17); la Constitución de Costa Rica requiere de $2 / 3$ para aprobar proyectos de ley sobre el Poder Judicial apartándose de la opinión de la Corte Suprema (artículo 167), para el financiamiento previo de las actividades electorales de los partidos políticos (artículo 96, letra e) y para establecer limitaciones al derecho de propiedad (artículo 45); y la Constitución belga dispone de un sistema de súper-mayoría para proteger los intereses de las diversas comunidades existentes (artículos 4, 5, 35, 39), para delegar materias de las comunidades a las autoridades locales autónomas, establecer las atribuciones de los municipios (artículo 24) y para el sistema electoral (artículo 68) 32 .

\footnotetext{
${ }^{28}$ Según el índice democrático 2011 de The Economist, todos los países recién citados pertenecen a la categoría de "democracia plena" ("full democracies"). En el "ranking” de las democracias más completas, Dinamarca está en tercer lugar, Austria en el decimotercero, Uruguay en el decimoséptimo, Estados Unidos en el decimonoveno, Costa Rica en el vigésimo y Bélgica en el vigesimotercero.

${ }^{29}$ U.S. Const., artículo II, $\$ 2$, cl. 2.

${ }^{30}$ De acuerdo al artículo 44 de la Constitución austriaca, estas "leyes constitucionales federales" son diferentes al texto formal de la Constitución de 1920 (reformado sustancialmente en 1929), aunque se ha estimado que ellas forman parte de la "constitución material” (como las leyes org. const. chilenas). Ellas son más de 100 y varias se encuentran contenidas dentro de leyes ordinarias. Elías MÉndEz, Cristina, El modelo constitucional austriaco desde la perspectiva de su integración con el Derecho de la Unión Europea, en Revista Constitucional de Derecho Europeo, 14 (Granada, 2010) 7, pp. 144145.

${ }^{31}$ Parte III, $\$ 20$ de la Constitución de Dinamarca de 1953.

${ }^{32}$ Por su parte, diversos tratados internacionales disponen que el Consejo de la Unión Europea requiere de mayorías calificadas (e incluso de unanimidad) para diversas materias. Aunque no se trata de un Estado, la lógica de la igualdad en la representación está presente en la organización política de la Unión Europea, razón por la
} 
Si los críticos se tomaran en serio la afirmación por la cual no puede existir una democracia verdadera debido a la existencia de un sistema de quórums súper-mayoritarios, entonces debieran aceptar una conclusión absurda: que en los sistemas recién citados no hay democracia ${ }^{33}$.

En realidad, la afirmación que señala que las leyes org. const. son contrarias a la democracia depende del tipo de democracia al que nos referimos. Esto lo reconoce el propio Fernando Atria cuando cita como ejemplo la democracia mayoritaria inglesa, que (casi) no tiene instrumentos contra-mayoritarios ${ }^{34}$. Este tipo de sistemas democráticos, sin embargo, son excepciones en los sistemas constitucionales contemporáneos, que en su mayoría admiten la existencia de herramientas contramayoritarias ${ }^{35}$. El problema de esta crítica es que descansa en presupuestos discutibles acerca de lo que una democracia $\mathrm{d}$ e b e s e r, por lo que no puede hacer suya la autoridad de definir lo que una democracia e $s$.

Sin perjuicio de lo anterior, comparto con estos autores que la regla general debe ser la mayoría simple, y que la súper-mayoría debe ser la excepción, por la misma razón que comparto la idea de que la constitución debe ser breve y regular pocas materias (los mínimos de la organización política). Los autores críticos han intentado demostrar que la mayoría simple se debe aplicar a todo lo que no forma parte de la constitución, pero no han construido una teoría que explique qué materias d e b e tener una constitución. Han dicho que lo contrario alteraría la igualdad (y citan a Böckenforde) pero para que ello tenga sentido deben conectarlo con alguna teoría de la representación política (cuestión que no han hecho) y con contestarle al propio Böckenforde

cual una crítica a la manera en que los votos se "ponderan" y no se "cuentan", también es posible. Tsebelis, George cit. (n. 20), pp. 329-330, y, aunque ya no se encuentra completamente actualizado, ver un análisis de las mayorías exigidas en el Consejo en García Lapresta, José Luis - Martínez Panero, Miguel, Incidencia de la ampliación de la Unión Europea en sus procedimientos de toma de decisiones, en Encuentro de Economía Pública (2001) [visible en internet: http://dialnet.unirioja.es/servlet/ articulo?codigo $=3142033$.

${ }^{33}$ Como ya lo advertí en la introducción, la doctrina nacional suele seguir los ejemplos de Francia y España, como ocurre con Silva Bascuñan, Alejandro cit. (n. 7), p. 26. Sin embargo, si bien los sistemas constitucionales de estos países fueron influyentes en el diseño de nuestra Constitución de 1980, ellos son malos ejemplos para comparar los quórums legislativos, ya que las mayorías legislativas que estas constituciones requieren, no son especialmente altas, incluso tratándose de las leyes orgánicas.

${ }^{34}$ ATRIA, F., cit. (n. 16), p. 175.

${ }^{35}$ El propio MuÑoz, F., cit. (n. 18), p. 122, parece reconocer este punto, donde señala que el constitucionalismo, en gran medida, es la limitación de la democracia. En esta afirmación, está claro que el profesor Muñoz se refiere a un tipo específico de democracia. 
acerca de la inconveniencia de regular por ley súper-mayoritaria aquellas materias que el mismo autor permite teóricamente ${ }^{36}$.

En cuarto lugar iv), ninguna de las críticas centra su análisis en las denominadas justificaciones especiales de las leyes org. const., cuestión que parece muy importante. Si, como Böckenforde (y Muñoz) reconocen, es legítimo que algunas materias sean reguladas por reglas súper-mayoritarias, entonces deben además explicar qué es lo que justifica lo anterior ${ }^{37}$. Sin embargo, el nivel de especificidad que logran se suele asociar a cuestiones que siguen siendo generales (como el ejemplo de la Constitución española, referida a los derechos fundamentales). Lo anterior es un error.

Como explicaré más adelante, todas las justificaciones generales de las leyes org. const. son dependientes de la importancia y particularidades de las materias específicas que ellas regulan. De esta manera, la pregunta del debate no debe ser si se justifican las leyes org. const., sino ¿en qué materias específicas es conveniente que el proceso legislativo se rigidice? Y esto sólo puede contestarse analizando casuísticamente los tipos de materia a regular. En consecuencia, no es lo mismo la ley orgánica constitucional sobre las Fuerzas Armadas y de Orden (artículo 105) que la ley orgánica constitucional del Tribunal Constitucional (artículo 92). Asimismo, la justificación de la regla de quórum para la modificación del sistema electoral difiere de manera sustancial de aquella que justifica la súper-mayoría en materia de municipalidades, o para el estatuto de la Contraloría General de la República. La división de justificaciones hace necesario separar los niveles del debate y, por consiguiente, no es correcto proponer la eliminación de un sistema de quórum súper-mayoritario sobre la base de argumentos que no consideren las particularidades específicas de las diversas materias propias de leyes org. const.

Por otra parte, la crítica a las leyes org. const. es necesaria ponderarla con otros argumentos que, siendo generales, justifican la regla súper-mayoritaria. En síntesis: i) las leyes org. const. hacen más difícil que el Ejecutivo tenga mayorías en el Congreso, lo que fortalece la independencia de este último ${ }^{38}$; ii) las leyes org. const. fortalecen el control político de las minorías con representación parlamentaria frente a eventuales abusos de las mayorías ${ }^{39} ; \mathrm{y}$

${ }^{36}$ Véase otra respuesta al argumento de la igualdad en Verdugo, Sergio, Regla de mayoria y democracia, cit. (n. 2), pp. 615-617.

${ }^{37}$ MuÑoz, F., cit. (n. 18), pp. 122-126, lo hace utilizando la tesis de Dworkin sobre los derechos, en contraste con la idea de Carl Schmitt de que la super-mayoría es antidemocrática.

${ }^{38}$ Verdugo, S., Control preventivo obligatorio, cit. (n. 2), pp. 622-623.

${ }^{39}$ Verdugo, S., Regla de mayoría y democracia, cit. (n. 2), pp. 623-626. Este argumento, y el anterior, han sido contestados por SzMULEWICZ, E., cit. (n. 16). 
iii) el ideal democrático es la unanimidad, pero como dicho mecanismo daría demasiado poder a los legisladores aislados y hace poco factible el desarrollo legislativo, la regla de súper-mayoría serviría como punto medio. Mientras más altos sean los quórums, más beneficiarios políticos de las reformas debieran existir y menos perdedores se debieran generar ${ }^{40}$. Lo anterior hace más probable que la legislación se encamine a producir bienes públicos.

Una adecuada orientación del debate debe perseguir un equilibrio entre el interés porque las mayorías gobiernen, con la excepcionalidad de las leyes org. const. para rigidizar determinadas materias con el objeto de proteger aquellos bienes que sean aceptables en una democracia.

\section{JUSTIFICACIONES GENERALES Y SISTEMA POLÍTICO}

Como ya se señaló, en la discusión sobre las leyes org. const. no basta con argumentar sobre la base de un fundamento general, sino que debe explicarse si el mismo debe (o puede) aplicarse a un caso especial. En esta sección, mostraré además que el plano general que se ha discutido en Chile es incompleto en sí mismo, esto es, que no se hace cargo de todos los elementos relevantes de este primer nivel de argumentación. Para ello, (1) analizaré la relación existente entre las leyes org. const. y el diseño mismo de la constitución; (2) examinaré la relación entre las leyes org. const. y otras instituciones contramayoritarias del sistema político ("veto players"); y (3) argumentaré que la solución adecuada debe ser casuística, ponderando los diferentes elementos aplicados al caso particular.

\section{Las leyes orgánicas constitucionales y el diseño de la constitución.}

Un adecuado diseño constitucional debe evaluar cuáles son los aspectos a los que se le va a entregar rigidez e, incluso, cuáles serán aquellos mínimos absolutos que no podrán ser afectados bajo ningún motivo. Una vez que las sociedades acuerdan estos puntos, ellas establecen un plan, contenido en la constitución, para administrar estos aspectos en el futuro y hacer frente a los procesos políticos que vendrán.

Si la opción política es la adopción de una democracia fundada en una constitución escrita que limite y estructure los poderes estatales y reconozca derechos fundamentales con carácter justiciable, normalmente los mínimos absolutos quedarán entregados al constituyente. Algunas constituciones dis-

\footnotetext{
${ }^{40}$ García, José Francisco, - Soto, Sebastián, Una teoría económica de la Constitución de 1980: Impacto sobre el proceso legislativo y acción de los grupos de interés, en Romero, Juan José - Rodríguez, Nicolás - Olivares, José Miguel (editores), José, Buen gobierno y corrupción: algunas expectativas, (Santiago, 2009), pp. 66 ss.; VERDUGo, S., Regla de Mayoría y Democracia, cit. (n. 2), pp. 626-629.
} 
ponen de ciertas cláusulas pétreas o intangibles (inmodificables) que limitan el proceso político de manera absoluta, pero la mayoría prefiere utilizar la rigidez como técnica para proteger esos mínimos sin que se prohíban las modificaciones (tan solo se establecen mayores escollos para las reformas, como un quórum alto, la aprobación de diferentes legislaturas, el consenso de diversos Estados miembros en una federación, etc.). Una cuestión importante en el diseño sobre la rigidez constitucional, dice relación con la extensión de las materias de que la constitución se hace cargo ${ }^{41}$. Algunas de ellas tendrán mayor densidad normativa que otras. Por ejemplo, la Constitución mexicana es mucho más extensa que la de los EE.UU., pero esta última es más difícil de modificar ya que su procedimiento de reforma tiene un procedimiento más exigente ${ }^{42}$. Sin embargo, la existencia de una jurisprudencia federal vinculante que interprete la Constitución ha dado contenido a muchas cláusulas breves de la Constitución de EE.UU., incrementando su extensión material y, por consiguiente, aumentando las áreas de rigidez. Otra diferencia importante entre ambas Constituciones, es que la tradición anglosajona del "common law", junto al poder de Cortes que tienen capacidad para interpretar la constitución, ha permitido que los procesos constitucionales de reforma se asocien a precedentes jurisprudenciales que modifican el sentido aplicado anterior de la Constitución de EE.UU., cuestión que suele no ocurrir en los países de tradición no anglosajona. Esto tiene un impacto importante en cualquier teoría sobre rigidez constitucional.

Una constitución menos rígida, dará más espacio lógico para que existan otros elementos de protección del sistema político. Una constitución más breve, entregará más posibilidades racionales para que su contenido sea complementado mediante el legislador o la jurisprudencia. En fin, cualquier diseño que se tenga será relevante para discutir sobre la manera en que la carta fundamental se relaciona con el resto del sistema político y normativo. Por eso, cuando la constitución sólo dispone un par de reglas aisladas para la regulación del Banco Central, y entrega el resto de la misma al legislador orgánico, ello probablemente tiene más sentido que en el caso del Tribunal Constitucional, donde la constitución desarrolla con bastante densidad su

${ }^{41}$ Sobre el diseño de la rigidez y la flexibilidad constitucional en general, véase el trabajo de Elkins, Zachary - Ginsburg, Tom - Melton, James, The Endurance of National Constitutions, en Cambridge University Press (Cambridge, 2009). Cabe hacer presente que la clasificación entre Constituciones flexibles y rígidas suele atribuirse a James Bryce.

${ }^{42}$ El procedimiento de reforma de la Constitución de los EE.UU. se encuentra en su artículo V. Sobre el proceso de reforma constitucional en México, véase MANCILla, Roberto. Derecho adjetivo constitucional (México, Editorial Liber Iuris Novum, 2012). 
organización, atribuciones e incluso procedimiento ${ }^{43}$. La justificación en un caso y en otro variará dependiendo de las opciones que el constituyente haya adoptado, lo que hace necesario un debate casuístico.

Los críticos del sistema de quórums especiales no suelen advertir con suficiente profundidad este tipo de diferencias. Como la idea original de las leyes org. const. era complementar el contenido de la constitución, debido a su carácter generalmente breve $e^{44}$, varios han llegado a sostener que estas normas son parte de una suerte de constitución material ${ }^{45}$. Para este grupo de autores, las leyes org. const. expandirían el ámbito de la constitución, dándole rigidez a la regulación de determinados aspectos relevantes que ella misma entrega al legislador ${ }^{46}$. Lo que ellos no suelen advertir, es que si se considera que estas normas tienen contenido "constitucional", entonces las mismas razones que justifican la rigidez constitucional podrían servir para fundamentar la rigidez de las leyes org. const. ${ }^{47}$. Por ello, para discutir sobre la conveniencia de tener leyes org. const., hay que debatir previamente sobre la necesidad de darle rigidez a una materia en particular, considerando el marco previo de tener una constitución que a veces regula con mayor detalle (como en el caso del Tribunal Constitucional) y otras no (como en el caso

${ }^{43}$ Por esto Zapata, P., cit. (n. 23), p. 401, tiene razón cuando señala que "el mismo objeto (de las ley org. const. ) se pudo haber logrado dándole a la propia Constitución Política una extensión mayor, haciendo que ella misma reglamentara con mayor detalle todos los aspectos jurídico-políticos más relevantes".

${ }^{44}$ Ver especialmente el debate de la Comisión de Estudios de la Nueva Constitución, sesión $\mathrm{N}^{\circ} 353$, de 19 de abril de 1978 . Bertelsen vinculó este punto con la necesidad de que este tipo de normas correspondan a la "expresión efectiva de la voluntad general”. Incluso algunos críticos de las leyes org. const. señalan que ellas “representan una suerte de 'Constitución en la sombras' que complementa el texto de la Constitución de 1980”. Couso, J. - Coddou, A., cit. (n. 16), p. 199.

${ }^{45}$ Una visión formalista nos diría que las leyes org. const. no forman parte del contenido material de la Constitución, ya que ellas provienen de la potestad legislativa, y no constituyente. Véase, por ejemplo, Ríos, L., cit. (n. 6), p. 41.

${ }^{46}$ Consecuencia de ello es, por ejemplo, que entre una norma constitucional y una orgánica constitucional hay una "diferencia política respecto de la entidad cuantitativa de la minoría protegida, pero no cualitativa”. Aldunate, Eduardo, El fin de la transición hacia una constitución de poca importancia, en ZÚÑIGA, Francisco (coordinador), Reforma constitucional (Santiago, LexisNexis [2005]), pp. 67-79. Véase también VERDugo, S., Regla de Mayoría y Democracia, cit. (n. 2), pp. 609-611.

${ }^{47}$ Parece ser un lugar común en la doctrina constitucional la conveniencia de tener una constitución rígida. Sin embargo, hay que hacer presente que $i$ ) ello no siempre es así en los hechos (ver por ejemplo la Constitución de Inglaterra); y ii) que esta materia se ha discutido por grandes intelectuales, donde destaca el debate sobre cuánto deben durar las constituciones, suscitado entre James Madison y Thomas Jefferson. Véase una buena narración de este debate en Elkins, Zachary - Ginsburg, Tom - Melton, James, cit. (n. 41), pp. 12-35. 
del Banco Central). La respuesta a estos problemas no definirá por si sola la conveniencia de adoptar una regla súper-mayoritaria, pero su definición es imprescindible para continuar examinando el resto de los aspectos que el debate debe considerar.

\section{Leyes orgánicas constitucionales e instituciones contra-mayoritarias.}

Además de la estructura de la constitución y de la necesidad de definir las materias a las que queremos entregar mayor protección (lo que responde al plano de las justificaciones especiales), la discusión sobre las justificaciones generales requiere del examen de la interrelación de varias instituciones que producen arreglos contramayoritarios, y que en algunos casos configuran un "jugador con veto" ("veto player") presente en el proceso legislativo. Entre otros: $i$ ) existen dos cámaras legislativas; $i$ ) posibilidad de paralizar un proyecto de ley por no ejercerse la facultad de darles urgencia; iii) el veto presidencial y la posibilidad de insistencia por parte el Congreso sólo cuando se reúne una súper-mayoría ${ }^{48} ; i v$ ) el control constitucional del Tribunal Constitucional en sus diferentes formas; $v$ ) las cuestiones de iniciativa exclusiva (unido al régimen de ideas matrices) que quitan capacidad legislativa a los parlamentarios ${ }^{49} ; v i$ ) las cuestiones reguladas directamente en la constitución; y vii) las leyes con exigencia de quórum súper-mayoritario.

Adicionalmente, y sin perjuicio de que todos los elementos anteriores se encuentran en otros sistemas políticos, desde el Derecho comparado también podemos observar otros arreglos institucionales que producen un efecto similar al del veto producido por la súper-mayoría, las que serían equivalentes a ellas. Entre estos mecanismos, encontramos la regla del "filibuster" del Senado estadounidense ${ }^{50}$ y el valor que se le asigna a las inasistencias de los parlamentarios a las sesiones ${ }^{51}$.

${ }^{48}$ Esta norma no es original de la Constitución chilena. Una disposición similar se encuentra en la Constitución de los EE.UU., artículo 1, S 7, cl. 2.

${ }^{49}$ Cabe hacer presente que este instrumento es anterior a la Constitución de 1980. Sobre la materia, ver Fermandois, Arturo - García, José Francisco, Origen del presidencialismo chileno: reforma constitucional de 1970, ideas matrices e iniciativa exclusiva, en Revista Chilena de Derecho, 36 (Santiago, 2009).

${ }^{50} \mathrm{El}$ "f i l i b u s t e r" es una forma en que el derecho a voz de los parlamentarios antes de someter a votación un proyecto de ley sirve para bloquear dicho proyecto. El parlamentario filibustero se extiende en su discurso de manera excesiva, y la única forma de obligarlo a terminar con su intervención y someter el proyecto de ley a votación, es mediante una super-mayoría. Producto de esta regla, y como explica Tsebelis, G. cit. (n. 20), p. 194: "el Senado de los Estados Unidos es una institución de mayoría calificada (o súper-mayoritaria)", debido a la posibilidad de obstrucción de un partido minoritario que controle 40 escaños (de un total de 100).

${ }^{51}$ Cuando se exige mayoría absoluta para aprobar un proyecto de ley, y todos asis- 
Todos los mecanismos anteriores se relacionan de manera dinámica en un proceso político donde participan varios actores interesados, y cada uno sigue fines diversos. Así, por ejemplo, el régimen de ideas matrices persigue evitar los abusos de parlamentarios observados en el pasado ${ }^{52}$, el control constitucional persigue reducir las posibilidades de que se vulnere la constitución y las normas sobre el procedimiento legislativo, el veto y la urgencia fortalecen el rol del presidente de la República en el contexto de un régimen presidencial reforzado, el bicameralismo promueve la deliberación y la especialización de las cámaras, etc. De alguna manera, todos ellos contribuyen a la existencia de escollos para modificar el statu quo, haciendo más difícil la acción de lobistas (que deben intentar capturar varias instituciones relacionadas) y reduciendo (sin eliminar) las posibilidades de generar reformas políticas profundas.

Uno podría observar el problema desde la perspectiva de la teoría de los frenos y contrapesos del poder político, que el constitucionalismo moderno promueve desde el Federalista ${ }^{53}$. Esta perspectiva se encuentra en tensión con una concepción de la democracia puramente mayoritaria, donde una mayoría simple toma las decisiones relevantes sin mayores contrapesos ni procedimientos que hagan excesivos los escollos de la decisión (como el de Inglaterra $)^{54}$. ¿Cuál de todas las opciones es la mejor?

ten, entonces la mayoría absoluta coincide con la mayoría simple. Si hay miembros ausentes, entonces la mayoría absoluta deja de ser simple y se vuelve calificada. Véase TSEBELIS, George cit. (n. 20), pp. 194-195. Este caso es aplicable a las leyes de quórum calificado chilenas, que podrían operar como reglas súper-mayoritarias en la práctica. Por ejemplo, si la mitad menos uno de los parlamentarios se ausentan ( 59 en la Cámara de Diputados), entonces se requerirá la unanimidad de los presentes (61 diputados).

${ }^{52}$ Ver Fermandois, A. - García, J. F., cit. (n. 49).

${ }^{53}$ Eso ha llevado a algunos profesores norteamericanos a argumentar que el establecimiento de reglas de quórum super-mayoritario a nivel legislativo calza con la estructura diseñada por el Federalista en la Constitución de los EE.UU. Sobre este interesante debate, véase MCGinnis, John - RAPpApORT, Michael, The Constitutionality of Legislative Supermajority Requirements: A Defense, en The Yale Law Journal, 105 (New Haven, 1995); KIng, Brett, The Use of Supermajority Provisions in the Constitution: The Framers, The Federalist Papers and the Reinforcement of a Fundamental Principle, en Seton Hall Constitutional Law Journal, 8 (s.l., 1998); MCGInNIs, John - RAPPAPORT, Michael, The Rights of Legislators and the Wrongs of Interpretation: A Further Defense of the Constitutionality of Legislative Supermajority Rules, en Duke Law Journal, 47 (Durham, 1997). Véase un argumento opuesto en Lieber, Benjamin - Brown, Patrick, On Supermajorities and the Constitution, en The Georgetown Law Journal, 83 (Washington, 1994); Lieber, Benjamin - Brown, Patrick, On Supermajorities and the Constitution, en The Georgetown Law Journal, 83 (Washington, 1994); y LEACH, Robert, House Rule XXI and an Argument Against Constitutional Requirement for Majority Rule in Congress, en UCLA Law Review, 44 (Los Angeles, 1997).

${ }^{54}$ Recuérdese que el mismo Federalista asignaba poco valor a la representación de 
No pretendo contestar esta pregunta mediante este trabajo. Sin perjuicio de ello, lo recién dicho nos permite inferir algunas consecuencias relevantes para el debate sobre las leyes org. const.: $i$ ) una eventual reforma al sistema de quórums debe considerar los efectos de la misma en el resto de los arreglos institucionales, y en la estructura de la constitución; ii) no puede dejar de analizarse el hecho de que haya materias donde hay mejores razones para tener rigidez que en otras; iii) sería saludable explorar eventuales reformas alternativas al sistema político para perseguir los fines que los críticos del sistema de leyes org. const. han invocado, y evaluar las diferentes fórmulas disponibles y su potencial efectividad ${ }^{55}$; y $i v$ ) la crítica política contra las leyes org. const. no debería contaminar la discusión técnica sobre los beneficios que la regla súper-mayoritaria entrega, dadas ciertas condiciones, al sistema político. Tenemos que preguntarnos si queremos seguir o no esos beneficios, los que forman parte del nivel de las justificaciones especiales. Además, debiéramos examinar otras alternativas de Derecho comparado, que permiten al legislador disponer de reglas súper-mayoritarias en aquellas leyes que estime especialmente importantes, como en el modelo austriaco (al que ya me referí brevemente) o el modelo que algunos han promovido en EE.UU., a propósito del denominado "plan Gingrich" 56 .

Hay al menos otras dos cuestiones que la doctrina nacional ha dejado de examinar: i) no ha considerado alguna teoría sobre la dinámica de las coaliciones políticas; y ii) no ha sido lo suficientemente profunda con la relación existente entre las súper-mayorías y el sistema electoral. En lo que queda de esta sección, explicaré por qué es importante considerar ambas cuestiones e inferiré algunas consecuencias que sirvan para orientar el debate en el futuro.

las mayorías legislativas. Se estimaba que ellas no eran otra cosa que "un imperfecto reflejo de la voluntad mayoritaria del pueblo en su conjunto”. McGinnis, J. - RAPPAPORT, M., The Constitutionality, cit. (n. 53), p. 508.

${ }^{55}$ Así, por ejemplo, y dentro de la fórmula que se elija, podría evaluarse la posibilidad de eliminar el control preventivo obligatorio debido a las razones que formulo en Verdugo, S., Control Preventivo Obligatorio, cit. (n. 2).

${ }^{56}$ En este plan, la mayoría republicana del Congreso de los EE.UU. discutió una regla para que los proyectos de ley que propusieran incremento de impuestos, debieran ser aprobados mediante la regla de $3 / 5$. Ello se hacía mediante una modificación a las reglas de la cámara, y no mediante una reforma constitucional. Ello originó un profundo debate acerca de la compatibilidad entre la estructura constitucional norteamericana y la regla de súper-mayoría. En materia tributaria, la súper-mayoría apunta a desincentivar la tendencia de los parlamentarios a beneficiar intereses específicos distribuyendo los costos en la población en general. McGinnis, J. - RAPPAPORT, M., The Constitutionality, cit. (n. 53), pp. 509-510. En Chile, este problema fue enfrentado con éxito mediante el régimen de la iniciativa exclusiva y las ideas matrices. 
i) En ciencia política se ha estudiado la teoría de la "mínima coalición ganadora"57 (en adelante, "mcg."), mediante la cual los políticos hacen lo necesario para ganar y consolidarse en el poder con la mayoría más baja posible (y de esa manera repartir los beneficios entre menos actores) ${ }^{58}$. De esta manera, por ejemplo, si bien un candidato presidencial requiere de una mayoría para ganar la elección y, en seguida, para impulsar su agenda política-legislativa, este candidato (y su coalición) tiene incentivos para que esa mayoría sea lo más pequeña posible, ojala la estrictamente necesaria para cumplir sus objetivos: la mcg. De esa manera, por ejemplo, asignará los ministerios y jefaturas de servicio entre militantes de pocos partidos políticos, teniendo más libertad de acción y concentrando más poder. De ser cierta la mcg., ¿cuál es el efecto que una regla súper-mayoritaria tendría en ella?

Si la agenda del presidente de la República es en alguna medida dependiente de la aprobación de leyes org. const., entonces probablemente la mcg. se vería afectada. Este jefe de Estado tendría el incentivo para que su sector de apoyo crezca, o para negociar con otros sectores. Para ganar una elección, el candidato presidencial requiere de una mayoría fuerte (para ganar en segunda vuelta) y para aprobar las leyes org. const. después, requerirá tener mayoría alta en el Congreso, debiendo conseguirla mediante los doblajes que permite el sistema electoral binominal, o pactando con sectores diferentes al suyo ${ }^{59}$. En cualquier caso, la regla súper-mayoritaria haría más costoso asumir lo que Ackerman denomina como "el modo de autoridad completa", por el cual una coalición pasa a tener el control del poder político ${ }^{60}$.

ii) Como ya lo adelanté algunas páginas atrás, varios críticos de las leyes org. const. han argumentado que ellas exigirían la generación de mayorías que muy difícilmente podrían producirse. Estos autores sostienen que lo anterior se debe a la tendencia al empate parlamentario que produce el sistema binominal de elecciones, el que haría imposible que las mayorías gobiernen la agenda legislativa por sí solas, requiriendo el acuerdo con algún sector de la minoría, por lo que la capacidad de "veto" de la minoría siempre estaría presente en este contexto ${ }^{61}$. Este análisis es cierto, pero incompleto.

${ }^{57}$ Esta expresión proviene del anglicismo "minimal winning coalition".

${ }^{58}$ Ver una breve pero clara explicación de lo anterior en COOTER, Robert, The Strategic Constitution, en Princeton University Press (New Jersey, 2000) pp. 73-75.

${ }^{59}$ Para Groseclose y Snyder, una regla súper-mayoritaria sería más fácil de conseguir que la mcg. Argumentan que la mcg. sólo ocurre de manera excepcional y rara. CooTER, R., cit. (n. 58).

${ }^{60}$ Ackerman, Bruce, La nueva división de poderes (México, Fondo de Cultura Económica, 2007).

${ }^{61}$ Zapata, P., cit. (n. 23), pp. 402-403; Couso, J. - Coddou, A., cit. (n. 16), p. 198; SZMulewicz, E., cit. (n. 18), p. 3 
Este problema es dependiente del sistema electoral y de la representación política, pero no de la regla súper-mayoritaria individualmente considerada ${ }^{62}$. A ello, hay que agregar dos cosas: $i$ ) en primer lugar, el propósito de la idea de las súper-mayorías legislativas hace necesario que la mayoría busque algún tipo de acuerdo con un sector de la minoría, por lo que el argumento del binominal sólo confirma algo que es perseguido por el diseño del quórum súper-mayoritario. La verdadera discusión no es el binominal, sino si este tipo de vetos de las minorías es deseable para ciertos casos o no. El debate sobre el sistema binominal responde a otras preguntas sobre representatividad y el sistema de partidos que queremos tener; y ii) En segundo lugar, el resto de los sistemas electorales actuarían de manera diferente respecto de las súpermayorías, pero quienes critican las leyes org. const. no han reparado en estos eventuales efectos hipotéticos. Un sistema proporcional, por ejemplo haría mucho más difícil alcanzar las mayorías necesarias para alcanzar un quórum tan alto $^{63}$. La literatura tradicional sobre los sistemas electorales coincide en que este tipo de sistemas tiende al multipartidismo ${ }^{64}$. Combinado con un sistema parlamentario, un sistema proporcional obliga a los partidos a pactar en coaliciones para generar un gobierno. En el contexto del sistema presidencial, el sistema proporcional agudiza los conflictos políticos atendido que es probable que el presidente de la República tenga minoría en el Congreso (o pierda la mayoría debido a parlamentarios descolgados $)^{65}$.

Considerando lo anterior, es poco probable que un sistema proporcional bajo un modelo presidencialista permita superar el problema que los críticos de las leyes org. const. denuncian respecto de las elecciones binominales para integrar el parlamento.

\section{El equilibrio de argumentos en el plano de las justificaciones generales.}

Por todo lo anterior, resulta saludable que el debate sobre las leyes org. const. en general no resuelva por sí solo el problema en casos particulares. Las propuestas en la materia debieran ofrecer fórmulas específicas que se hagan cargo de los elementos señalados.

Es conveniente que en el debate se ponderen $i$ ) la necesidad de mantener el statu quo mediante obstáculos a la reforma de estatutos concretos; ii) la

${ }^{62}$ Verdugo, S., Regla de Mayoría y Democracia, cit. (n. 2), pp. 618-619.

${ }^{63}$ Este sistema es muy popular entre varios de los críticos de las leyes org. const., de allí que sea importante profundizar en él.

${ }^{64}$ Se trata, por supuesto, de una tendencia teórica y no de una regla empírica absoluta. Sobre el debate de los efectos de los sistemas electorales, véase, entre muchos otros, a Nohlen, Dieter, Sistemas electorales y partidos políticos (México, Fondo de Cultura Económico, 1994), pp. 105-115.

${ }^{65}$ Ackerman, B., cit. (n. 61), p. 37. 
institución llamada a velar por ese statu quo (el Tribunal Constitucional, las minorías políticas u otros); iii) la posibilidad de que la rigidización origine conflictos políticos y sociales de mayor envergadura; y $i v$ ) la técnica más apropiada para conseguir los fines específicos que se dice perseguir.

Por lo anterior, resulta un buen ejemplo el informe que emitió la Comisión Europea para la Democracia mediante el Derecho (también denominada "Comisión de Venecia") sobre la nueva Constitución de Hungría ${ }^{66}$. Dicha Constitución consagró un sistema legislativo donde un tipo específico de leyes (las "leyes cardinales") requieren de los $2 / 3$ de los parlamentarios presentes para su creación y modificación. La Constitución de Hungría contiene más de 50 referencias a dichas leyes. En su informe, la "Comisión de Venecia" estimó que el sistema de "leyes cardinales" es inconveniente debido a su amplio uso. La Comisión estimó que varias de las materias entregadas a este tipo de leyes requieren de un pronunciamiento constitucional más preciso, y otras debieron ser entregadas a leyes ordinarias ${ }^{67}$. La recomendación de la Comisión es restringir los ámbitos de las leyes cardinales a aquellas áreas donde haya fuertes justificaciones para requerir una mayoría legislativa tan alta.

Como puede verse, la Comisión no cuestiona la técnica de súper-mayoría legislativa, sino el mal uso de ella. Se asume que la constitución juega un rol preponderante en el sistema jurídico y que la regla general debe ser la legislación ordinaria. Las excepciones, para la Comisión, son admisibles, pero deben estar justificadas. Esta es, justamente, la dirección que el debate chileno debe seguir.

\section{JUSTIFICACIONES ESPECIALES DE LAS LEYES ORGÁNICAS CONSTITUCIONALES}

Un argumento a favor de la regla legislativa súper-mayoritaria sólo puede considerarse completo una vez que el segundo nivel (el nivel especial) haya sido agotado. En otras palabras, no basta con explicar por qué es importante tener una regla súper-mayoritaria en sí, sino que además hay que fundamentar por qué dicha regla es conveniente en el caso particular de una materia específica. En esta sección, no pretendo realizar un examen cabal de todas y cada una de las materias que el constituyente ha asignado al legislador orgánico. Para que mi punto esté demostrado, basta con examinar algunos casos relevantes de materias propias de ley org. const. y revisar si existen buenas razones aplicadas a los mismos.

\footnotetext{
${ }^{66}$ European Commission for Democracy through Law ("Venice Commission"), Opinion on the New Constitution of Hungary, Opinion N $N^{\circ} 618,2011,29$ pp.

${ }^{67}$ Ibíd., pp. 6-7, puntos 22 al 27.
} 
Previo a ello, cabe hacer presente que la necesidad de la argumentación especial no deriva solamente de las ideas presentadas en este trabajo, sino que ella ha estado presente en el pasado. Así, por ejemplo, el propio Jaime Guzmán explicaba, en cuanto al sistema de quórums diseñado por la Comisión de Estudios de la Nueva Constitución: "la exigencia aumenta a medida que se acentúa la importancia de las normas respectivas" ${ }^{68}$. Por su parte, Lautaro Ríos reconoce que las leyes org. const. regulan "importantes instituciones jurídico-políticas" ${ }^{69}$, que es lo que parece distinguir a las mismas del resto de las leyes ordinarias. Dentro de los críticos, Fernando Muñoz ha reconocido que hay casos en que una regla súper-mayoritaria se justifica atendida su relevancia ${ }^{70}$. En este reconocimiento, está implícita la idea de que las mayorías calificadas no son necesariamente contrarias a la democracia o, al menos, que hay espacios legítimos donde la democracia mayoritaria no cabe ${ }^{71}$.

Sin embargo, el reconocimiento tácito de que las justificaciones especiales son necesarias, no ha significado avanzar en la forzosa casuística del problema, cuestión de la que pretendo hacerme cargo, examinando brevemente algunos casos puntuales. Entre ellos, revisaré la necesidad especial de que exista una regla de super-mayoría para (1) los órganos de control del poder político (Poder Judicial, Contraloría General de la República y Tribunal Constitucional); (2) el sistema electoral y el Tribunal Calificador de Elecciones (en adelante, el “TRICEL”); (3) otros órganos independientes (Banco Central, Ministerio Público y otros órganos autónomos de carácter local); y (4) Congreso Nacional y proceso legislativo.

\section{1. Órganos de control del poderpolitico (Poder Judicial, Contraloría General} de la República y Tribunal Constitucional)

La Carta Fundamental dispone que algunos organismos que están llamados a controlar al poder político, o a limitar el ejercicio del poder, sean regulados por una ley org. const. Este es el caso la organización y atribuciones de los tribunales (artículos 77, 78 y 82), de la Contraloría General de la República (artículos 98 y 99) y del Tribunal Constitucional (artículo 92 y 93).

${ }^{68}$ Comisión de Estudios de la Nueva Constitución, sesión $\mathrm{N}^{\circ} 389$, de 27 de junio de 1978.

${ }^{69}$ Por ejemplo, Ríos, L., cit. (n. 6), p. 40; Bulnes, L., cit. (n. 6), pp. 230-232; y Caldera, H., cit. (n. 6), p. 455.

${ }^{70}$ Ver, por ejemplo, MuÑoz, F., cit. (n. 18), pp. 123-126. Para este autor, la regla súper-mayoritaria puede defenderse para la regulación de los derechos fundamentales. Para ello, utiliza el ejemplo de la Constitución española, a la que podría sumarse la práctica de las leyes constitucionales austriacas sobre derechos fundamentales.

${ }^{71}$ Este punto ya lo desarrollé en Verdugo, S., Regla de Mayoría y Democracia, cit. (n. 2), pp. 617-618. 
Los tres órganos del Estado que menciono cumplen un rol importante en la limitación del ejercicio del poder de los gobernantes. Se trata de instituciones cuyas atribuciones suelen estar en tensión con las facultades del presidente de la República y del Congreso, y que sin embargo tienen poca influencia en el diseño regulatorio de sus estructuras. Así, por ejemplo, los tribunales pueden declarar nulo un decreto o resolución, pero no pueden defenderse del Ejecutivo cuando este promueve reformas legales amenazando sus poderes. El Tribunal Constitucional puede declarar inconstitucional una ley, pero carece de potestad para defender sus facultades y controlar su propio marco de acción. La Contraloría General de la República puede representar un decreto, pero no puede defender sus poderes frente a una ley que declare exentos del trámite de la toma de razón la actividad de algún órgano estatal ${ }^{72}$. Como puede verse, los poderes de control de estos órganos son vulnerables frente al poder político ${ }^{73}$.

Además, tanto el Ejecutivo como el Legislativo tienen fuertes incentivos para amenazar las atribuciones de estos órganos. El legislador no quiere que le declaren inconstitucional la ley, el presidente de la República no quiere que le declaren nulo un decreto, los ministros de Estado quieren que nadie los controle cuando participan en actos públicos favoreciendo los candidatos de su coalición política en época de campañas electorales, y un funcionario público no quiere que la Contraloría General de la República le abra un sumario. Por eso, la vulnerabilidad de los poderes de los órganos de control es especialmente alta. Frente a ello, normalmente las constituciones utilizan diferentes técnicas que estimulan la autonomía de estos órganos. Así, por ejemplo, en EE.UU. los poderes de la Corte Suprema federal tienen rango constitucional, y ella misma determina el alcance sus facultades mediante una jurisprudencia obligatoria con precedente general; y en Costa Rica las leyes sobre el Poder Judicial deben ser aprobadas por 2/3 si el legislador se quiere apartar de la opinión de la Corte Suprema (artículo 167).

Este tipo de técnicas fortalecen las atribuciones de los órganos de control dentro del sistema político y jurídico, y promueven la autonomía con que este

${ }^{72}$ En general, la doctrina de los administrativistas ha prestado poca atención a las razones que justifican la existencia de una ley org. const. en el caso de la Contraloría General de la República. Véase, por ejemplo, Silva Cimma, Enrique, Derecho administrativo chileno y comparado. El control público (Santiago, Editorial Jurídica de Chile, 1994), pp. 169.171; y Cordero, Luis, El control de la Administración del Estado (Santiago, LegalPublishing, 2009), pp. 49-55.

${ }^{73}$ Sobre una teoría más acabada de la independencia judicial, véase Ferejohn, John, Independent Judges, Dependent Judiciary: Explaining Judicial Independence, en Southern California Law Review, 72 (Los Angeles, 1998); y Ferejohn, John - KrAMER, Larry, Independent Judges, Dependent Judiciary: Institutionalizing Judicial Restraint, en New York University Law Review, 77 (New York, 2002). 
tipo de instituciones actúa, generando mejores niveles de "accountability" entre nuestras autoridades y produciendo información relevante que la ciudadanía debiera conocer ${ }^{74}$. Los electores deben saber si un político cometió un ilícito, si un servicio público paga precios por sobre el valor del mercado, o si un ministro de Estado está extralimitándose en sus funciones.

El constituyente de 1980 se hizo cargo de este problema mediante diferentes mecanismos, como $i$ ) el hecho de que algunos de los poderes de control se encuentren en el propio texto original de la Constitución, y otros han sido agregadas mediante reforma constitucional ${ }^{75}$; ii) el que ninguna de estas materias pueda ser objeto de legislación delegada (artículo 64); iii) el que exista una norma por la cual la Corte Suprema debe ser oída cuando se promueva algún proyecto de ley sobre atribuciones u organización de los tribunales ${ }^{76}$ (artículo 77); y iv), el constituyente también dispuso el mecanismo de que la regulación complementaria de estos órganos de control fuera entregada a normas propias de una ley org. const.

Como en Chile no existe precedente vinculante, como ocurre en EE.UU., los tribunales no pueden interpretar sus propios poderes de una manera generalmente obligatoria y con autoridad constitucional. Por lo anterior, resulta posible que los poderes políticos amenacen las facultades de estos órganos de control mediante la reforma de sus atribuciones simplemente legales. Esta amenaza cobra mayor importancia cuando se trata de poderes que no están definidos con mucha precisión por la Constitución, como ocurre con la superintendencia de la Corte Suprema (artículo 82), o cuando los poderes de control se subordinan al ámbito que el legislador señale, como ocurre con el trámite de la toma de razón de la Contraloría General de la

${ }^{74} \mathrm{No}$ es casualidad, por ejemplo, que el constituyente derivado haya dispuesto que las excepciones al principio de publicidad de los actos y resoluciones de los órganos del Estado deban estar establecidas en una ley de quórum calificado que aplique algunas de las causales que el propio constituyente ha dispuesto de manera taxativa (artículo 8). Cabe hacer presente que utilizo la expresión anglosajona "accountability", por no existir un sinónimo preciso en castellano. Dicha palabra proviene del latín accomptare ("a cuenta") y de computare ("calcular"). El término se asocia a una combinación de elementos como la responsabilidad, el escrutinio, la transparencia, la rendición de cuentas y el control.

${ }^{75}$ Es el caso de los poderes que recibió el Tribunal Constitucional en la reforma constitucional de 2005, de la Ley N 20.050 (artículo 93).

${ }^{76}$ Es sólo una garantía para que la Corte Suprema sea oída. A diferencia de Costa Rica, esta garantía no genera un efecto concreto en la manera en que el proyecto de ley será redactado. En la historia de la norma, en la Comisión de Estudios de la Nueva Constitución se indicó que este el propósito de este mecanismo no es establecer una suerte de facultad de veto, sino que es valioso que la Corte Suprema tenga algún nivel de participación. Sesión $N^{\circ}$ 333, de 14 de diciembre de 1977. 
República (artículo 99) 77 . Por otra parte, la amenaza se hace menos importante cuando la propia Constitución precisa el contenido de las atribuciones mediante cláusulas autoejecutables, como ocurre con los poderes del Tribunal Constitucional (artículo 93) ${ }^{78}$.

En cualquier caso, la exigencia de que las modificaciones a las leyes org. const. de estos órganos sea hecha mediante normas súper-mayoritarias, obliga a que se busque un consenso con una parte de la minoría. Atendida nuestra estructura presidencial, lo frecuente es que el interesado en amenazar los poderes de estos órganos sea el Poder Ejecutivo, como ocurre cuando la población le reprocha responsabilidad por el aumento de los índices de criminalidad y denuncia, y este se ve frustrado frente a la actividad de jueces de garantía que son reacios a aplicar la medida de prisión preventiva. En este tipo de casos, el Ejecutivo (principal responsable de la conducción política del país) tiene incentivos para amenazar los poderes y la organización de los órganos de control, y si tuviera las mayorías necesarias para hacerlo, su capacidad de amenaza crecería frente a jueces que se suponen independientes.

Por esto, cuando se dispone que las modificaciones legales respectivas requieren acuerdo con parte de la minoría opositora, en caso que el Ejecutivo tuviera mayoría simple (pero no calificada) en el Congreso, las minorías parlamentarias podrían controlar la conveniencia de este proyecto modificatorio ${ }^{79}$. Ellas podrían defender las atribuciones de los órganos de control, o podrían llegar a algún tipo de acuerdo con el Gobierno de turno. Esta herramienta permite disuadir y moderar la manera en que el Ejecutivo se relaciona con estos órganos, lo que les permite ser más independientes en su actuar.

Por lo anterior, no es extraño que parte de la doctrina defienda las leyes org. const. en materia de tribunales de justicia. Así, por ejemplo, José Luis Cea ha dicho que el objetivo de esta ley org. const. se debe a la protección del "axioma de la separación de poderes [...]"80; y Emilio Pfeffer ha señalado que

77 “[...] el Contralor General tomará razón de los decretos y resoluciones que, en conformidad a la ley, deben tramitarse por la Contraloría [...]” (artículo 99).

${ }^{78}$ Sin perjuicio de ello, a Ortúzar le pareció "lógico" dejar la regulación del Tribunal Constitucional a una ley org. const. Véase: Comisión de Estudios de la Nueva Constitución, sesión $\mathrm{N}^{\circ}$ 415, de 28 de septiembre de 1978.

${ }^{79}$ Por eso, la "evidencia empírica corrobora la expectativa de que la independencia del poder judicial aumenta en función de los jugadores con veto": TSEBELIS, G., cit. (n. 20), p. 300

${ }^{80}$ A continuación, CEA, José Luis, Tratado de la Constitución de 1980 (Santiago, Editorial Jurídica de Chile, 1988), p. 272. agrega: "Por eso, ni el Presidente de la República ni el Congreso pueden, en caso alguno, ejercer funciones judiciales, avocarse causas pendientes, revisar los fundamentos o contenido de sus resoluciones o hacer revivir proceso fenecidos. De allí que, además, la organización, atribuciones y régimen de los funcionarios del Poder Judicial sean propios de una ley orgánica constitucional”. 
la ley org. const. de los tribunales se explica por la "trascendencia del Poder Judicial en la vida institucional del país" ${ }^{\prime 1}$.

\section{Sistema electoral y Tribunal Calificador de Elecciones.}

La Constitución dispone que varios aspectos del sistema electoral deben ser regulados por una ley org. const. (artículos 18 inciso $1^{\circ}, 26,47,49^{82}, 113$, 119), a los que posteriormente se adicionó el registro electoral (artículo 18, inciso $2^{\circ}$, Ley $\mathrm{N}^{\circ} 20.337$ ) y el sistema de primarias (artículo $19, \mathrm{~N}^{\circ} 15$, Ley $\mathrm{N}^{\circ}$ 20.414) por el constituyente derivado. Así, también, dispone que el Tribunal Calificador de Elecciones, órgano jurisdiccional que juega un rol relevante en la aplicación de las normas sobre el sistema electoral, sea regulado por una ley org. const. (artículo 95).

No hay muchos antecedentes que expliquen el propósito de estas normas en su origen, salvo por alguna referencia superficial ${ }^{83}$, sin perjuicio de que el propio Tribunal Constitucional haya valorado las mismas con argumentos que no profundizan mayormente en la finalidad de que las normas del sistema electoral sean reguladas por una ley org. const. ${ }^{84}$. Por eso, las justificaciones (u objetivos) que describo más abajo, no son necesariamente las

Cabe hacer presente que Cea dice esto no sólo respecto de la ley org. const., sino que también respecto de la prohibición de dictar decretos con fuerza de ley en la materia.

${ }^{81}$ Pfeffer, Emilio, Manual de Derecho constitucional, (Santiago, Editorial Jurídica Ediar ConoSur Ltda, 1990), II, p. 206.

${ }^{82}$ Varias de estas disposiciones han sido modificadas, especialmente cuando se decidió eliminar las bases constitucionales del sistema binominal para las elecciones parlamentarias, el que quedó entregado a la respectiva ley org. const., la que tiene un quórum más alto que el común del resto de las leyes org. const. Véase la actual disposición decimotercera transitoria de la Constitución.

${ }^{83}$ En efecto, en la Comisión de Estudios de la Nueva Constitución no hubo mayores antecedentes (véase sesión № 413, de 20 de septiembre de 1978). Por su parte, en el Consejo de Estado se estimó que el "padrón electoral es de importancia esencial", por lo que debiera quedar comprendido dentro de la ley org. const. del artículo 18 (sesión $\mathrm{N}^{\circ}$ 100 , de 8 de enero de 1980).

${ }^{84} \mathrm{El}$ Tribunal Constitucional ha señalado que: la amplitud de las materias que la Constitución entrega a esta ley sobre 'sistema electoral público', a diferencia de lo que ocurre con otras leyes del mismo rango en las cuales la Constitución ha sido definitivamente más restrictiva, se justifica, sin duda, por su especial importancia y trascendencia, pues, como bien se ha dicho, "una de las bases de la institucionalidad consagrada en la Constitución Política reside en la organización republicana y democrática de gobierno, en el cual el ejercicio de la soberanía, además del que corresponde a las autoridades que establece la Constitución, se realiza por el pueblo mediante elecciones periódicas y plebiscitos. De esta base fundamental derivan la ciudadania y los principales derechos que ella otorga, el de sufragio y el de optar a cargos de elección popular, los cuales, por antonomasia, constituyen los derechos politicos" (Informe de la Comisión de Estudio de Leyes Orgánicas Constitucionales relativo al Anteproyecto de Ley Orgánica Constitucional sobre Siste- 
que se tuvieron la a vista en el diseño de la regla de quórum, sino más bien buenas justificaciones que hoy podrían darse para la regla súper-mayoritaria en esta materia.

Por otra parte, hay que recordar que en otros países con democracias consolidadas es común encontrar este tipo de normas de quórum alto para el sistema electoral. Así, por ejemplo, la Constitución belga entrega varias materias electorales a una regla súper-mayoritaria de 2/3 (artículo 68); la de Uruguay sigue una regla parecida de $2 / 3$ (artículo $77 \mathrm{~N}^{\circ} 7$ y 12); y la Constitución de Costa Rica establece que si un proyecto de ley en materia electoral va en contra de la opinión del Tribunal Supremo de Elecciones, este (también) requerirá del quórum de 2/3 (artículo 97) ${ }^{85}$.

El objetivo de estas normas de quórum es producir un sistema electoral que entregue ciertas garantías democráticas a los actores políticos relevantes. De esta manera, se pretende que dicho régimen de elecciones no quede a disposición de mayorías que tienen incentivos para incrementar su propio poder alterando las reglas del juego político. Por el contrario, si algunas materias electorales quedaran a merced de simples mayorías, estas tendrían la tendencia a modificar las reglas del juego en beneficio propio. Los perjudicados por estas modificaciones serían las minorías parlamentarias. Así, por ejemplo, las mayorías podrían alterar las normas distritales para modificar el denominado "mapa electoral" y favorecer a sus propios candidatos ${ }^{86}$, buscando terminar con los doblajes de la minoría y reuniendo electores para producir doblajes propios (en el caso de la elección de parlamentarios) o para acumular votos en listas comunes (en el caso de la elección de concejales). Así también, las mayorías podrían buscar una fórmula electoral que beneficie sus intereses, amenazar los poderes del Tribunal Calificador de Elecciones, disponer de mayores costos de entrada a nuevos actores que desafían a las autoridades en ejercicio y vulnerar el principio constitucional de igualdad electoral contenido en el artículo 18.

Con la regla súper-mayoritaria, sin embargo, para generar cambios al sistema electoral las mayorías deben producir acuerdos con una parte de la minoría parlamentaria, por lo que al menos se asegura que no habrá muchos perdedores y que existirá un freno a un posible abuso. El argumento general del control a las mayorías y de la promoción de frenos y contrapesos, cobra

ma Electoral Público enviado a S.E. el Presidente de la República el 29 de noviembre de 1985). Tribunal Constitucional, rol $N^{\circ} 53$, de 5 de abril de 1988, considerando $4^{\circ}$.

${ }^{85}$ Otra norma de súper-mayoría que contiene la Constitución de Costa Rica, opera para el financiamiento de las actividades electorales de los partidos políticos (artículo 96, letra e).

${ }^{86}$ Esta práctica se conoce con un anglicismo conocido entre nosotros: el "gerrymandering". 
especial importancia en este caso. Cabe hacer presente que esto no ha servido para proteger a los independientes (para ello se requeriría una regla de unanimidad, lo que no es factible ni conveniente), cuestión que tampoco se produciría en un escenario de mayoría simple ${ }^{87}$.

Uno de los problemas más importantes en la regulación del sistema electoral, es que parte de los regulados por dicho sistema (los candidatos) son

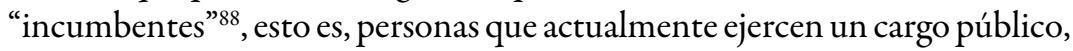
y que tienen interés en permanecer en él (mediante la reelección) o en que otros de su mismo grupo lo ejerzan. Por eso, los parlamentarios en ejercicio tienen incentivos para beneficiarse como grupo y perjudicar a los candidatos desafiantes. Ninguna regla de mayoría (ni simple, ni súper-mayoritaria, ni siquiera la unanimidad) pueden poner término a esta situación. Sin embargo, un quórum más alto puede incrementar las posibilidades de que las minorías denuncien con un voto útil las prácticas abusivas de los incumbentes. Probablemente la mejor manera de lidiar con el problema de los incumbentes sea observando un conjunto relacionado de otros arreglos institucionales (bicameralismo, la aprobación de otro ente, veto presidencial y límite a la reelección, por ejemplo), pero no puede desconocerse que la regla de quórum juega un rol significativo.

Existen otras maneras de regular el siempre complejo sistema electoral de manera de reducir el poder de las mayorías simples (e incumbentes) para beneficiarse con el régimen que ellos administran, pero probablemente la más aceptada es la del quórum súper-mayoritario. Por esta misma razón, muchas constituciones protegen las bases del sistema electoral estableciéndolas en sus textos, y dándoles a ellas la rigidez de la propia constitución. Esta también es

${ }^{87}$ En el denominado caso "descolgados", las mayorías parlamentarias aprobaron una norma que perjudicaba a los candidatos independientes, exigiendo un mayor plazo para que ellos pudieran inscribirse como tales a partir de la renuncia a sus militancias políticas. Con ello, los partidos políticos ganaron poder en perjuicio de los candidatos independientes, cuestión que fue declarada constitucional por el Tribunal Constitucional. Véase Tribunal Constitucional, rol N²062, de 27 de septiembre de 2011. En este caso, la exigencia súper-mayoritaria de ley org. const. fue insuficiente, atendido que los independientes en el Congreso no alcanzan una capacidad de veto suficiente dentro del proceso legislativo. Otro caso relevante para mencionar es la reforma constitucional del año 2005, de la Ley $\mathrm{N}^{\circ} 20.050$, donde se dispuso que las vacantes parlamentarias se proveerán con quien indique el partido político respectivo, y que aquellas vacantes que dejen parlamentarios independientes, no serán proveídas, salvo que este hubiera integrad una lista con algún partido político, caso en el cual se vuelve a la primera regla de reemplazo (artículo 51).

${ }^{88}$ Cabe señalar que la expresión "incumbentes" no está reconocida por al Diccionario de la Real Academia, pese a que ella es muy común en algunos textos de ciencia política. Ella proviene del anglicismo "incumbent", que se asocia a aquella persona que actualmente detenta un cargo público. 
una solución de súper-mayoría. Nuestro constituyente, en cambio (y sobre todo después de la reforma de 2005, que eliminó el sistema binominal de la carta fundamental), determinó un camino intermedio, mediante el cual parte del sistema electoral está en la Constitución (el artículo 25 y 113, por ej.) y parte en un grupo de leyes org. const. Este camino intermedio parece sensato atendidas las razones expuestas recién.

Alguien podría criticar (como se ha hecho) que la regla de súper-mayoría debe eliminarse, debido a que con ella se protege el statu quo, cuya legitimidad de origen es cuestionada. Con esta crítica, el actual sistema electoral estaría diseñado para proteger un determinado grupo en perjuicio de otro. Aunque esta crítica sólo puede ser aplicable al sistema binominal, si ella prosperara cualquier otro sistema electoral que se quiera establecer tendría el mismo problema de ausencia de rigidez y posibilidad de abuso por las mayorías. La protección del statu quo es relevante en esta materia, aunque no absoluta. Por eso una posición intermedia entre la rigidez más alta (la de la constitución) y la más baja (la de la ley), es importante para cualquier nuevo sistema que se proponga. Sólo así dicho sistema podría asegurar un consenso amplio, de manera de garantizar la menor cantidad de perdedores posibles, maximizando la cantidad de ganadores. Por ello, las críticas contra el sistema electoral binominal no deben contaminar la existencia de una regla de quórum súper-mayoritario.

Lo anterior es sin perjuicio de aquello que señalé en la sección sobre las justificaciones generales, donde argumenté que el sistema electoral es relevante para la operatividad de las mayorías en el Congreso y debe, por lo tanto, ser considerado a la hora de rediseñar estos arreglos institucionales.

\section{Ministerio Público, Banco Central y órganos autónomos de carácter local.}

Junto con la defensa de la autonomía de los órganos de control, la Constitución también regula algunos órganos que, por razones diferentes, se espera que gocen de independencia. De esta manera, aquélla dispone que el Ministerio Público (artículos 84, 88 y 91) y el Banco Central (artículo 108) estén dotados de la garantía de la súper-mayoría. En ambos casos, el constituyente persigue evitar que los poderes políticos puedan intervenir fácilmente, fortaleciendo una autonomía que (con buenas o malas razones) se quiso defender.

En el caso del Ministerio Público, el constituyente derivado indicó que la existencia de una ley org. const. se vinculó al "grado de independencia, autonomía y responsabilidad de los fiscales en la dirección de la investigación y en el ejercicio de la acción penal pública" ${ }^{89}$. De esta manera, se persigue que los

89 "Mensaje" de la Ley de reforma constitucional N 19.519. 
fiscales puedan cumplir con las funciones que la propia Carta Fundamental establece, de acuerdo al principio de objetividad, mediante el cual deben investigar los hechos que acrediten la culpabilidad, y también aquellos que demuestren la inocencia del imputado.

Por su parte, la Ley orgánica constitucional del Banco Central fortalece una autonomía que tiene por objeto estimular su carácter técnico ${ }^{90}$. El propósito de separar la política monetaria, cambiaria y crediticia de la política fiscal, y de entregar las tres primeras a un organismo independiente del poder político, que funcione con criterio técnico, apunta a que la emisión del dinero y las políticas cambiarias no sean objeto de manipulación política por parte del Ejecutivo. De esta manera, la regulación constitucional del Banco Central (no sólo de su ley orgánica constitucional) tiene por objetivo "asegurar la racionalidad económica, el control de la inflación y la exclusión de la demagogia en la regulación de la economía de Chile" ${ }^{\prime 1}$.

Atendidos los objetivos señalados, el constituyente (derivado en un caso y originario en el otro), decidió reforzar la autonomía constitucional de estos órganos mediante la rigidez de su normativa complementaria. La exigencia de una ley org. const., de esta manera, viene a proteger a estos órganos frente al poder de los políticos, especialmente respecto del Ejecutivo. Es este último (el Ejecutivo), quien tiene los mayores incentivos para interferir en las políticas de estos órganos autónomos. La técnica de las leyes org. const. asegura que el Presidente de la República, cuando quiera amenazar los poderes de los órganos autónomos, deba contar con el acuerdo de parte importante del Congreso, incluyendo la mayoría de las veces a una fracción relevante de la oposición. Ello asegura que existirá un control político en las modificaciones a las leyes de ambos órganos.

Por una parte, la experiencia chilena demuestra que el Ejecutivo ha tenido cierta tendencia a financiar programas sociales mediante emisiones inorgánicas de dinero, lo que genera inflación y pobreza, y le da un (para algunos perverso) interés en intervenir en la política monetaria. Por otra parte, el Ejecutivo es el responsable de la política criminal del país, por lo tanto tiene un fuerte estímulo para mostrar números favorables a la ciudadanía. De esta manera, el Ejecutivo suele estar del lado de las víctimas, formando parte del aparato persecutor del Estado. Sin embargo, tanto al Ministerio Público como al Banco Central se les pide que actúen con autonomía respecto de

${ }^{90}$ La historia de la norma no aporta muchos antecedentes. Véase Comisión de Estudios de la Nueva Constitución, sesión $\mathrm{N}^{\circ} 399$, de 12 de julio de 1978, y sesión $\mathrm{N}^{\circ}$ 384, de 14 de junio de 1978. En el Consejo de Estado tampoco hay muchos antecedentes del motivo de la Ley orgánica constitucional del Banco Central. Véase sesión $\mathrm{N}^{\circ} 97$, de 27 de noviembre de 1979.

${ }^{91}$ CEA, J. L., cit. (n. 86), p. 51. 
las necesidades políticas del Gobierno de turno, por lo que la intervención del Ejecutivo es normalmente rechazada. Si el Ejecutivo quiere modificar los estatutos de ambos órganos (Banco Central y Ministerio Público), debe contar con una mayoría calificada, por lo que se reduce su capacidad de amenaza frente a los poderes de estos órganos.

Esta situación la genera la regla de súper-mayoría. Algunos pueden estar en contra de la autonomía del Banco Central (quieren politizar la política monetaria) o de la independencia del Ministerio Público (quieren darle más poder al Ejecutivo en la política criminal), y esos serían fines legítimos. Sin embargo, estos argumentos se dirigen a la autonomía de estos órganos, y no a sus leyes org. const. directamente. Considerando que en este caso las leyes org. const. no son más que una técnica destinada a fortalecer la independencia de estas instituciones, la defensa de las justificaciones especiales depende de la aceptación de un supuesto previo: la necesidad de darle a estos órganos dicha autonomía. Sólo aceptando dicho supuesto podrá discutirse si la técnica de la súper-mayoría es apropiada para fortalecerla, cuestión que creo acertada.

Cabe hacer presente que, no obstante lo señalado en los párrafos precedentes, la necesidad de una ley org. const. no es equivalente en ambas instituciones. En el caso del Banco Central, el texto constitucional es muy breve, ya que se limita a reconocer algunas características de la institución y a disponer algunas prohibiciones importantes en su actuar. En este caso la Carta Fundamental no dice nada en lo relativo a la dirección orgánica del Banco, ni se refiere a sus funciones y atribuciones. Estas cuestiones son importantes para la operatividad de la autonomía del Banco, por lo que el rol de la ley org. const., en este caso, es relevante. En el caso del Ministerio Público no ocurre lo mismo, ya que el constituyente se ha preocupado de determinar con mayor precisión la estructura orgánica y las funciones de dicha institución. La ley org. const., por consiguiente, juega un rol menos relevante que en el caso del Banco Central.

Por otra parte, la Constitución también ordena que algunos órganos de identificación local, que gozan de autonomía constitucional, sean regulados por leyes org. const. En estos casos, si bien los argumentos para la autonomía son diferentes a los esbozados respecto del Ministerio Público y del Banco Central, la técnica de las ley org. const. se dirige al mismo fin: evitar que el Gobierno central afecte los poderes de ciertos órganos que no tienen facultad de veto en el proceso legislativo. Estos casos son relativamente comunes en el Derecho comparado. Normalmente, los Estados F e d e r a l e s le entregan competencias a los Estados fe d e r a d o s a través de su constitución federal, lo que representa una protección fuertemente rígida. Otros Estados unitarios lo hacen mediante mecanismos similares al chileno. Así, por ejemplo: i) la Constitución de Uruguay dispone del quórum de 2/3 para fijar límites 
(artículo artículo 85, $\mathrm{N}^{\circ}$ 9); y ii) la Carta Fundamental belga exige 2/3 para que las comunidades deleguen facultades a uno o más órganos autónomos y para disponer las atribuciones de los Municipios y de los órganos intramunicipales (artículos 24 y 41 ).

La Constitución chilena sigue un camino similar al indicado. Primero dispone que el Estado de Chile es unitario, y luego establece niveles de descentralización y regionalización (artículo 3), para lo cual crea gobiernos locales autónomos que carecen de poderes para intervenir en el proceso legislativo, y cuya regulación complementaria generalmente está entregada auna ley org. const. Ello lo hace para la determinación y modificación de comunas, provincias y regiones (artículo 110), para la regulación de los Gobiernos y Consejos Regionales (artículos 113, 114, 115, 125) y para las Municipalidades (artículos 118, 119, 120, 121, 122, 125). Asimismo, mediante una reforma constitucional se dispuso que los estatutos especiales de los territorios de Isla de Pascua y del archipiélago Juan Fernández, debían ser regulados por una ley org. const. (artículo 126 bis, Ley $\left.\mathrm{N}^{\circ} 20.193\right)^{92}$.

En todos los casos anteriores, las instituciones locales relacionadas forman parte de la Administración del Estado (descentralizada) y ejercen funciones públicas dentro de sus respectivos territorios. Estas atribuciones pueden competir con las facultades de la Administración centralizada, por lo que se pueden originar conflictos, especialmente en la asignación de recursos. Además, es posible que un número importante de autoridades locales pertenezcan coaliciones políticas que no simpatizan con los conductores de la Administración centralizada, por lo que esta última puede tener el estímulo de favorecer a algunas en perjuicio de otras. Todo este juego político que existe a nivel local se regula mediante leyes donde las autoridades locales suelen no tener influencia y carecen de poder formal. Sin embargo, el jefe de la Administración central es el principal legislador, que a veces consigue mayorías para legislar y desarrollar su programa político. Ello vuelve al Presidente de la República en la principal amenaza de la función local.

\footnotetext{
${ }^{92}$ En la historia de la Ley № 20.573, Reforma Constitucional sobre territorios especiales de Isla de Pascua y Archipiélago Juan Fernández, algunos constitucionalistas discutieron si era apropiado o no que la regulación complementaria fuera entregada a una ley org. const. Zúñiga estimó que era una mala idea, ya que las leyes org. const. debían ser excepcionales y eran contrarias al principio democrático (Documento de la Biblioteca del Congreso Nacional: "Historia de la Ley No 20.573: Reforma Constitucional sobre territorios especiales de Isla de Pascua y Archipiélago Juan Fernández”, p. 61). Nogueira indicó que las leyes org. const. son comunes en el Derecho comparado y que esta ley org. const. "puede constituir en un mecanismo efectivo para garantizar el respeto de los derechos fundamentales" (p. 64). Por su parte, y representando al Ejecutivo, Patricio Rosende también defendió la idea de establecer una ley org. const. con el objeto de no dejar a los derechos fundamentales a merced de "mayorías circunstanciales" (p. 66).
} 
Frente a ello, la exigencia de una ley súper-mayoritaria favorece el control sobre las mayorías, favoreciendo la autonomía de estos entes locales que compiten con el Gobierno central. Al igual que en el caso del Ministerio Público y del Banco Central, para discutir si la ley org. const. es una técnica adecuada, debe aceptarse el supuesto de que la independencia de estos órganos es valiosa. En el caso de las autonomías locales, sin embargo, los argumentos para dicha autonomía son de diversa naturaleza (reconocimiento de culturas indígenas, identificación local, representación política más cercana, eficiencia en la administración de ciertos servicios, etc.).

\section{Congreso Nacional y proceso legislativo.}

La Constitución le entrega al legislador orgánico la regulación de varios aspectos del Congreso Nacional (artículos 47, 49, 52, 55) y del proceso legislativo y de reforma constitucional (artículos 54, 74, 128), normas que son complementadas con los reglamentos internos de las cámaras (artículo 56). A diferencia de otras materias entregadas a la ley org. const., en este caso sí encontramos antecedentes relevantes en el origen del mandato constitucional. De hecho, la idea de establecer un sistema de leyes org. const. nació justamente a propósito del tratamiento del Congreso ${ }^{93}$.

La propia Constitución regula con bastante detalle la composición del Congreso, sus atribuciones y la manera en que se desarrolla el proceso legislativo. Por eso, el fundamento de la regulación no puede ser la brevedad general con que la Constitución trata la materia. Por eso, y sin perjuicio de que existen algunas excepcionales cuestiones relevantes para la dinámica del proceso legislativo cuya regulación no es detallada en la Constitución ${ }^{94}$, en el origen de la norma el propósito de la ley org. const. descansaba en otra razón: la importancia de esta materia para el sistema político y legislativo ${ }^{95}$.

${ }^{93} \mathrm{El}$ mismo Bertelsen argumentaba que el procedimiento legislativo no puede ser regulado, en su plenitud, por la Constitución, por lo que es necesaria una ley org. const. Comisión de Estudios de la Nueva Constitución, sesión 344, 4 de abril de 1978.

${ }^{94}$ Ello ocurre, por ejemplo, con el caso de las urgencias legislativas, las que son claves para entender la influencia del presidente de la República en su calidad de colegislador. Otro ejemplo lo constituyen las normas para la admisibilidad de las indicaciones parlamentarias, las que inciden en el ejercicio de los poderes legislativos de los parlamentarios.

${ }^{95}$ En efecto, en la Comisión de Estudios de la Nueva Constitución, Bertelsen usó la regulación del congreso como ejemplo de una materia que consideraba "importante" para entregarla a una ley org. const., como es la regulación de los vetos a los proyectos de ley. En esa ocasión, se agregaba que por su carácter político, esta materia no podía ser objeto de un recurso de inaplicabilidad, ya que está "intimamente relacionada con la organización política”. Comisión de Estudios de la Nueva Constitución, sesión N ${ }^{\circ} 353$ del 19 de abril de 1978. 
La densidad normativa del texto constitucional no resuelve, como es obvio, todos los detalles del capítulo referido al Congreso Nacional. Y si la materia es esencialmente importante para el sistema político, y aceptamos el supuesto de que los principales actores políticos tienen un interés concreto y visible respecto de esta regulación, entonces es posible inferir que los detalles, en este caso, son también importantes ${ }^{96}$.

Los principales regulados por la ley org. const. del Congreso son los propios legisladores (los parlamentarios y el presidente de la República). En consecuencia los regulados controlan y administran su propia regulación. Recordemos que, si bien el Tribunal Constitucional juega un rol relevante en el control previo de las modificaciones legales a esta regulación, es muy difícil (por no decir imposible) que sea procedente el control represivo tanto respecto de la ley org. const. ${ }^{97}$ como respecto de los reglamentos de las cámaras $^{98}$, lo que vuelve al legislador en el árbitro de su propia regulación, una vez que esta se encuentra vigente ${ }^{99}$.

En estas condiciones, si el presidente de la República tiene una mayoría simple y leal en el Congreso, y no existieran normas propias de una ley org. const., este pasaría a tener el control de la regulación. Ello es desaconsejable, ya que la regulación de estas normas tiene por objeto un aspecto esencial de nuestra democracia (nada menos que el ejercicio procedimental de la manera en que la ciudadanía es representada por el legislador) que no debe alterarse. Si una facción política tuviera el control de esta regulación, tendría muchos incentivos para dejar de representar a la ciudadanía e imponer sus intereses propios, desobedeciendo normas elementales del proceso legislativo.

${ }^{96}$ Por eso mismo la Comisión de Venecia acepta que leyes súper-mayoritarias de $2 / 3$ regulen el procedimiento legislativo. Véase European Commission for Democracy through Law, cit. (n. 66), punto 24.

${ }^{97}$ Para que proceda este tipo de control, habría que generar una "gestión pendiente”, cuestión muy compleja de construir debido al contenido de las materias contenidas en la ley org. const. del Congreso. ¿Qué disposiciones podrían ser relevantes judicialmente como para ser utilizadas en una "gestión pendiente" de manera que el precepto legal cuestionado sea decisivo para la resolución del asunto? Sería una suerte de "caso de laboratorio" poco probable de construir.

${ }^{98}$ En este caso el único camino que se me ocurre es el de la nulidad de derecho público, con todas las dificultades que ello significa.

${ }^{99}$ Con la salvedad de que procederá el control eventual de constitucionalidad cuando existan reclamos sobre la manera en que proyectos de ley están siendo actualmente tramitados (artículo 93, $\mathrm{N}^{\circ}$ 3). No se trata de un control sobre la norma en sí, sino que de la aplicación de la Constitución durante el procedimiento. Por eso, este control eventual no permite que el Tribunal Constitucional analice la constitucionalidad de la ley que regula el procedimiento legislativo ni la organización y atribuciones del Congreso, sus cámaras y la intervención legislativa del presidente de la República. La constitucionalidad de este tipo de leyes es sólo preventiva. 
En esto, la exigencia super-mayoritaria de la ley org. const. juega un rol relevante. Las minorías parlamentarias con capacidad de veto pueden controlar a una mayoría que persigue modificar la ley org. const. en su beneficio propio, lo que debiera producir una legislación donde haya pocos actores políticos perdedores. De esta manera, la regulación procedimental de nuestra democracia asegura la existencia probable de control político al interior del legislativo. Con ello, se garantiza de mejor forma que las reglas del juego político tengan algún nivel de imparcialidad y que, cuando exista una oposición minoritaria al Gobierno de turno, esta no será perjudicada de manera abusiva, por ejemplo, alterando la manera en que se resuelve la admisibilidad de una indicación parlamentaria o en que se ejerce la función fiscalizadora de la Cámara de Diputados. Así, la función de control de la oposición no pierde fuerza, y con ello nuestro sistema democrático gana en "accountability".

\section{CONCLUSIONES}

1. Existen diferentes maneras de orientar el debate sobre las leyes org. const., uno general y otro especial. El debate chileno sólo se ha quedado en el nivel general y no ha entrado a analizar los argumentos especiales que justifican las leyes org. const. en particular. Por otra parte, la manera en que los críticos han argumentado en el nivel general adolece de deficiencias importantes: ellos suelen no considerar el resto de los arreglos institucionales relevantes del sistema ni considera (ni pondera) los bienes que la técnica de las leyes org. const. está llamada a servir.

2. Las regla súper-mayoritaria a nivel legislativo es una técnica constitucional que sigue distintos fines, y que se relaciona con otros instrumentos del sistema político. Varios países han utilizado este tipo de instrumento, ya sea de manera directa (elevando los quórums de ciertas leyes) o de manera indirecta (disponiendo otros mecanismos contramayoritarios que producen efectos similares). Sin embargo, cualquier análisis que se haga no puede eludir la necesidad de considerar el proceso político y las facultades de los diferentes "jugadores con veto" que participan en él (bicameralismo, veto presidencial, control constitucional, etc.).

3. Hay buenas razones para argumentar que en nuestro sistema político tenemos un exceso de "jugadores con veto" en el proceso legislativo, pero esas razones no conducen necesariamente a la necesidad de eliminar las reglas de quórum súper-mayoritario. Estas razones deben hacernos pensar en el diseño de un modelo equilibrado que siga con efectividad los fines que queremos perseguir (estabilidad para ciertas materias, autonomía para ciertos órganos, etc.). Previo a ello, la discusión sobre los fines es imprescindible y, sin em- 
bargo, aún no la hemos tenido con suficiente profundidad. No es saludable discutir sobre la técnica adecuada (las leyes org. const. son una técnica) antes de definir los fines que queremos promover.

4. En este trabajo, he mostrado que las leyes org. const. promueven determinados fines que no pueden disociarse de las justificaciones especiales, esto es, de las razones que caso a caso fundamentan la existencia de la regla súpermayoritaria. Así, he analizado brevemente algunas de estas justificaciones, explicando por qué ellas tienen relevancia en el caso del sistema electoral, de ciertos órganos de control del poder político, de algunas instituciones cuya autonomía queremos fortalecer y del estatuto del Congreso Nacional.

Si bien estos ejemplos no agotan la discusión, ellos permiten mostrar que existen buenas razones para tener quórums súper-mayoritarios de manera casuística y excepcional. Estas razones, sin embargo, varían en el caso a caso. Así, por ejemplo, mientras la ley org. const. del sistema electoral y el Congreso Nacional persiguen evitar que las mayorías simples alteren las reglas del juego político en perjuicio de minorías políticas relevantes (quitándole imparcialidad al sistema político), las leyes org. const. sobre órganos de control del poder (como la Contraloría General de la República y el Tribunal Constitucional) y las que regulan ciertas instituciones cuya autonomía valoramos (Banco Central y Municipalidades, por ejemplo) persiguen fortalecer la independencia de las mismas frente a actores políticos que tienen fuertes incentivos para amenazar los poderes de dichos órganos. Dependiendo del caso particular, con la protección de dicha autonomía se persigue promover diversos fines, como elevar los niveles de "accountability" del poder político e incrementar el grado de representación local.

\section{BIBLIOGRAFÍA}

Ackerman, Bruce, La nueva división de poderes (México, Fondo de Cultura Económica, 2007).

Aldunate, Eduardo, Problemas del control preventivo de constitucionalidad de las leyes, en Revista de Estudios Constitucionales, 1 (Talca, 2005) 3.

Aldunate, Eduardo, El fin de la transición hacia una constitución de poca importancia, en ZÚÑIga, Francisco (coordinador), Reforma Constitucional (Santiago, Lexis Nexis [2005]).

Atria, Fernando, Participación y alienación politica: el problema constitucional, en Fuentes, Claudio (editor), Nombre del pueblo: debate sobre el cambio constitucional en Chile (Santiago, Heinrich Böll Stiftung - ConoSur e ICSO Diego Portales [2010]).

Bassa, Jaime, Democratización y mutación constitucional, en Cazor, Kamel - Salas, Carolina (coordinadores), Estudios Constitucionales (Santiago, Asociación Chilena de Derecho Constitucional, Librotecnia [2010]). 
BORDALÍ, Andrés, Análisis critico del control preventivo y represivo de constitucionalidad de las normas jurídicas por los tribunales constitucionales, en NogUeIRA, Humberto, Jurisdicción constitucional en Chiley América Latina: presente y prospectiva (Santiago, LexisNexis [2005]).

Buchheister, Axel - Soto Sebastián, Criterios para la calificación de normas orgánico constitucionales en la jurisprudencia del Tribunal Constitucional, en Revista Chilena de Derecho, 32 (Santiago, 2005).

Bulnes, Luz, La ley orgánica constitucional, en Revista Chilena de Derecho, 11 (Santiago, 1984).

CAldera, Hugo, Ley orgánica constitucional y potestad reglamentaria, en Revista Chilena de Derecho, 11 (Santiago, 1984).

CEA, José Luis, Tratado de la Constitución de 1980 (Santiago, Editorial Jurídica de Chile, 1988).

Cooter, Robert, The Strategic Constitution, en Princeton University Press (New Jersey, 2000).

Cordero, Luis, El control de la Administración del Estado (Santiago, LegalPublishing, 2009).

Correa, Rodrigo, Tribunal Constitucional, en Revista de Derecho de la Universidad Adolfo Ibáñez, 2 (Santiago, 2005).

Couso, Javier - Coddou, Alberto, Las asignaturas pendientes de la reforma constitucional chilena, en Fuentes, Claudio (editor), en Nombre del pueblo: debate sobre el cambio constitucional en Chile, (Santiago, Heinrich Böll Stiftung - ConoSur e ICSO Diego Portales [2010]).

Cruz-Coke, Carlos, Manual de educación civica ( $8^{a}$ edición, Santiago, Ediciones Universidad del Desarrollo, 2005).

De la Fuente, Felipe, Problemas de quórum en la tramitación de las leyes interpretativas de la Constitución, orgánicas constitucionales y de quórum calificado, en Revista de Derecho de la Universidad Católica de Valparaiso, 14 (Valparaíso, 1992).

Elkins, Zachary - Ginsburg, Tom - Melton, James, The Endurance of National Constitutions, en Cambridge University Press (Cambridge, 2009).

Elías Méndez, Cristina, El modelo constitucional austriaco desde la perspectiva de su integración con el Derecho de la Unión Europea, en Revista Constitucional de Derecho Europeo, 14 (Granada, 2010) 7.

Ferejohn, John, Independent Judges, Dependent Judiciary: Explaining Judicial Independence, en Southern California Law Review, 72 (Los Angeles, 1998).

Ferejohn, John - Kramer, Larry, Independent Judges, Dependent Judiciary: Institutionalizing Judicial Restraint, en New York University Law Review, 77 (New York, 2002).

Fermandois, Arturo - García, José Francisco, Origen del presidencialismo chileno: reforma Constitucional de 1970. Ideas matrices e iniciativa exclusiva, en Revista Chilena de Derecho, 36 (Santiago, 2009).

Fuentes, Claudio, Elites, opinión pública y cambio constitucional, en Fuentes, Claudio (editor) en Nombre del Pueblo: Debate Sobre el Cambio Constitucional en Chile (Santiago, Heinrich Böll Stiftung - ConoSur e ICSO Diego Portales [2010]).

García, Gonzalo, Reformas politicas presentadas por el Ejecutivo, en Couso, Javier (editor), Anuario de Derecho Público (Santiago, Ediciones Universidad Diego Portales, 2011).

García Lapresta, José Luis - Martínez Panero, Miguel, Incidencia de la amplia- 
ción de la Unión Europea en sus procedimientos de toma de decisiones, en Encuentro de Economia Pública (2001) [visible en internet: http://dialnet.unirioja.es/servlet/ articulo?codigo $=3142033]$.

García, José Francisco - Soto, Sebastián, Una teoría económica de la Constitución de 1980: Impacto sobre el proceso legislativo y acción de los grupos de interés, en ROMERO, Juan José - Rodríguez, Nicolás - Olivares, José Miguel (editores), José Buen gobierno y corrupción: algunas expectativas, (Santiago, 2009).

Groseclose, Tim - Syder, James, Buying Supermajorities, en American Political Science Review, 90 (ciudad, 1996) 2.

Henrí uez, Miriam, Las fuentes formales del Derecho, (Santiago, LegalPublishing, 2009).

KIng, Brett, The Use of Supermajority Provisions in the Constitution: The Framers, The Federalist Papers and the Reinforcement of a Fundamental Principle, en Seton Hall Constitutional Law Journal, 8 ( $1^{\text {st }}$ sem., 1998).

LEACH, Robert, House Rule XXI and an Argument Against Constitutional Requirement for Majority Rule in Congress, en UCLA Law Review, 44 (Los Angeles, 1997).

Lieber, Benjamin - Brown, Patrick, On Supermajorities and the Constitution, en The Georgetown Law Journal, 83 (Washington, 1994).

MCGinnis, John - RAPPAPORT, Michael, The Constitutionality of Legislative Supermajority Requirements: A Defense, en The Yale Law Journal, 105 (New Haven, 1995).

MCGINnIS, John - RAPPAPORT, Michael, The Rights of Legislators and the Wrongs of Interpretation: A Further Defense of the Constitutionality of Legislative Supermajority Rules, en Duke Law Journal, 47 (Durham, 1997).

Mancilla, Roberto. Derecho adjetivo constitucional (México, Editorial Liber Iuris Novum, 2012).

MuÑoz, Fernando, Leyes Orgánico-constitucionales. Insatisfactoria rigidización de la democracia, en Anuario de Derecho Constitucional Latinoamericano, 1 (2006).

Nohlen, Dieter, Sistemas electorales y partidos politicos (México, Fondo de Cultura Económico, 1994).

Pfeffer, Emilio, Manual de Derecho constitucional,(Santiago, Editorial Jurídica Ediar ConoSur Ltda, 1990) II.

PfefFer, Emilio, Algunos problemas que se derivan del control obligatorio de constitucionalidad que ejerce el Tribunal Constitucional sobre las leyes orgánicas constitucionales, en Ius et Praxis, 1 (Santiago, 1998) 4.

Ríos, Lautaro, Las leyes orgánicas constitucionales, en Revista Chilena de Derecho, 10 (Santiago, 1983).

Rubenfeld, Ruben, Rights of Passage: Majority Rule in Congress, en Duke Law Journal, 46 (Durham, 1996).

SHAPIRO, Martín, Revisión judicial a priori y a posteriori: los modelos norteamericano y europeo, en Revista Chilena de Derecho, 20 (Santiago, 1993).

Sierra, Lucas - MAC-CluRE Lucas, Frente a las mayorias: leyes supramayoritarias y Tribunal Constitucional en Chile (Santiago, Centro de Estudios Públicos, 2011).

Silva Bascuñán, Alejandro, Tratado de Derecho constitucional (Santiago, Editorial Jurídica, 2000), VII.

Silva Cimma, Enrique, Derecho Administrativo chileno y comparado. El control público (Santiago, Editorial Jurídica de Chile, 1994).

Szmulewicz, Esteban, Democracia, gobierno de la mayoría y leyes orgánicas constitu- 
cionales. Parte I, Asuntos Públicos, Informe 954, 2012-I [visible en internet: http:// www.asuntospublicos.cl/wp-content/uploads/2012/04/954.pdf].

ToHÁ, Carolina, Constitución y Bicentenario: la superación de un déficit histórico, en Fuentes, Claudio (editor). En Nombre del Pueblo: Debate Sobre el Cambio Constitucional, en Chile (Santiago, Heinrich Böll Stiftung-ConoSur e ICSO Diego Portales, [2010]).

TSEBELIs, George, Jugadores con veto: cómo funcionan las instituciones politicas (México, Editorial Fondo de Cultura Económica, 2006).

Verdugo, Sergio, Control preventivo obligatorio: auge y caída de la toma de razón al legislador, en Revista de Estudios Constitucionales, 1 (Talca, 2010).

Verdugo, Sergio, Regla de mayoria y democracia: el caso de las leyes orgánicas constitucionales, en Revista Actualidad Jurídica, 20 (Santiago, 2009).

Zapata, Patricio, Justicia constitucional (Santiago, Editorial Jurídica de Chile, 2008). Actas de la Comisión de Estudios para la Nueva Constitución

Actas del Consejo de Estado

The Economist, Democracy index 2011, report from the Economist Intelligence Unit, 48 pp. [visible en: https://www.eiu.com/public/topical_report.aspx?campaignid=D emocracyIndex2011].

Biblioteca del Congreso Nacional, "Historia de la Ley No 20.573. Reforma Constitucional sobre territorios especiales de Isla de Pascua y Archipiélago Juan Fernández", $176 \mathrm{pp}$.

European Commission for Democracy through Law ("Venice Commission"), Opinion on the New Constitution of Hungary., Opinion N ${ }^{\circ} 618,2011,29$ pp. 